\title{
KLUM@GTAP: Introducing Biophysical Aspects of Land-Use Decisions into a Computable General Equilibrium Model a Coupling Experiment
}

\author{
Kerstin Ronneberger • Maria Berrittella • \\ Francesco Bosello • Richard S. J. Tol
}

Received: 29 September 2006 / Accepted: 2 September 2008 / Published online: 4 October 2008

(C) The Author(s) 2008. This article is published with open access at Springerlink.com

\begin{abstract}
In this paper, the global agricultural land use model Kleines Land Use Model is coupled to an extended version of the computable general equilibrium model (CGE) Global Trade Analysis Project in order to consistently assess the integrated impacts of climate change on global cropland allocation and its implication for economic development. The methodology is innovative as it introduces dynamic economic land-use decisions based also on the biophysical aspects of land into a state-of-the-art CGE; it further allows the projection of resulting changes in cropland patterns on a spatially more explicit level. A convergence test and illustrative future simulations underpin the robustness and potentials of the coupled system. Reference simulations with the uncoupled models emphasise the impact and relevance of the coupling; the results of
\end{abstract}

K. Ronneberger $(\bowtie)$

Deutsches Klimarechenzentrum $\mathrm{GmbH}$,

Bundesstr. 55,

20146 Hamburg, Germany

e-mail: ronneberger@dkrz.de

K. Ronneberger $\cdot$ R. S. J. Tol

Research Unit Sustainability and Global Change, Hamburg

University and Centre for Marine and Atmospheric Science,

Bundesstr. 55,

20146 Hamburg, Germany

K. Ronneberger

International Max Planck Research School

on Earth System Modelling,

Hamburg, Germany

M. Berrittella

Centro Interdipartimentale di Ricerche sulla Programmazione

Informatica dell'Economia e delle Tecnologie (CIRPIET),

University of Palermo,

Viale delle Scienze,

90128 Palermo, Italy coupled and uncoupled simulations can differ by several hundred percent.

Keywords Land-use change Computable general equilibrium modeling · Integrated assessment .

Climate change $\cdot \mathrm{C} 68 \cdot \mathrm{R} 14 \cdot \mathrm{Q} 17 \cdot \mathrm{Q} 24$

\section{Introduction}

Land use is one of the most important links of economy and biosphere, representing a direct projection of human action on the natural environment. Large parts of the terrestrial land surface are used for agriculture, forestry, settlements and infrastructure. Among these, agricultural production is still the

\author{
F. Bosello \\ Fondazione Eni Enrico Mattei, (FEEM), \\ Castello 5252, \\ 30122 Venice, Italy \\ e-mail: francesco.bosello@feem.it
}

F. Bosello

Department of Economics Business and Statistics,

Università Statale di Milano,

Via Conservatorio 7,

20122 Milan, Italy

e-mail: francesco.bosello@unimi.it

R. S. J. Tol

Institute for Environmental Studies, Vrije Universiteit,

Amsterdam, The Netherlands

R. S. J. Tol

Engineering and Public Policy, Carnegie Mellon University, Pittsburgh, PA, USA 
dominant land use accounting for 34\% of today's land surface [14], compared to forestry covering $29 \%$ [6] and urban area which is taking less than $1 \%$ of the land surface [9]. On the one hand, agricultural management practices and cropping patterns have a vast effect on biogeochemical cycles, freshwater availability and soil quality; on the other hand, the same factors govern the suitability and productivity of land for agricultural production. Changes in agricultural production directly determine the development of the world food situation. Thus, to consistently investigate the future pathway of economic and natural environment, a realistic representation of agricultural land-use dynamics on the global perspective is essential.

Traditionally, land-use decisions are modelled either from an economic or geographical perspective. Geographical models focus on the development of spatial patterns of land-use types by analysing land suitability and spatial interaction. Allocation of land use is based either on empirical-statistical evidence or formulated as decision rules based on case studies and 'common sense'. They add information about fundamental constraints on the supply side, but they lack the potential to treat the interplay between supply, demand and trade endogenously. Economic models focus on drivers of land-use change on the side of food production and consumption. Starting out from certain preferences, motivations, market and population structures, they aim to explain changes in land-intensive sectors. The biophysical aspects of land as well as the spatial explicitness of land-use decisions are commonly not captured in such models. A new branch of integrated models seek to combine the strengths of both approaches in order to make up for their intrinsic deficits. This is commonly done by coupling existing models, which describe the economy to a biosphere model, or by improving the representation of land in economic trade models. For a more detailed discussion of different approaches to large-scale land-use modelling, see [10].

We present here the coupled system KLUM@GTAP of the global agricultural land-use model KLUM [18] with GTAP-EFL model, which is an extended version of the GTAP [11]. The main aim of the coupled framework is to improve the representation of the biophysical aspects of land-use decisions in the computable general equilibrium model (CGE). This is the first step towards an integrated assessment of climate change impacts on economic development and future crop patterns.

A similar approach was realised in the EURURALIS project [12], where the integrated model to assess the global environment (IMAGE) $[1,16,23]$ has been coupled to a version of GTAP with extended land use sector [21]. In this coupling, the change in crop and feed production, determined by GTAP, is used to update the regional demand for crops and pasture land in IMAGE. Then, IMAGE allocates the land such as to satisfy the given demand, using land productivities, which are updated by management induced yield changes as determined by GTAP. The deviation of the different changes in crop production determined by the two models is interpreted as yield changes resulting from climatic change and from changes in the extent of used land. ${ }^{1}$ These yield changes together with an endogenous feed conversion factor are fed back to GTAP. The land allocation is modelled on grid level by means of specific allocation rules based on factors such as distance to other agricultural land and water bodies.

Our approach differs in several ways. In our coupling, the land allocation is exogenous in GTAP-EFL and replaced by KLUM. The land-use decisions are limited to crops, excluding livestock. Instead of crop production changes, we directly use the crop price changes determined in GTAPEFL. Our allocation decisions are not based on allocation rules aiming to satisfy a defined demand but are modeled by a dynamic allocation algorithm, which is driven by profit maximisation under the assumption of risk aversion and decreasing return to scales. This ensures a strong economic background of the land allocation in KLUM.

Another approach to introduce biophysical aspects of land into economic model is the so-called agro-ecological zones (AEZ) methodology [3, 8]. According to the dominant climatic and biophysical characteristics, land is subdivided into different classes, reflecting the suitability for and productivity of different uses. GTAP is currently extending its databases and models to include such an improved representation of land, known as GTAP-AEZ [13]. From this, our approach differs in three crucial ways. The standard version of GTAP has one type of land, whereas the land use version has 18 types of land. The 18 land types are characterised by different productivities. Each GTAP region has a certain amount of land per land type and uses part of that. The first difference is that we have a more geographically explicit representation of land. Like GTAP-AEZ, KLUM@GTAP has aggregate land use, but unlike GTAP-AEZ, KLUM@GTAP has spatially disaggregated land use as well. The allocation algorithm of KLUM is scale-independent. In the present coupling, KLUM is calibrated to country-level data, but Ronneberger et al. [17] use KLUM on a $0.5 \times 0.5^{\circ}$ grid (for Europe only). The second difference is that KLUM@GTAP does not have land classified by different productivity but that productivities vary continuously over space, again allowing the direct coupling to large scale crop growth models [17] to simulate implications of environmental changes. In GTAP-AEZ, a change in e.g. climate or soil quality requires an elaborate reconstruction of the land database. A third difference is that KLUM@GTAP has consistent land transitions. In

\footnotetext{
${ }^{1}$ A change in the extent implies a change in the yield structure of the used land
} 
GTAP and GTAP-AEZ, a shift of land from crop A to crop $\mathrm{B}$ implies a (physically impossible) change in area; this drawback is the result from calibrating GTAP to value data (KLUM@GTAP uses area) and from normalising prices to unity and using arbitrary units for quantities.

In the next section, we outline the basics of GTAP-EFL and KLUM. The greatest challenge of the coupling is to guarantee the convergence of the two models to a common equilibrium. In Section 3, we describe the coupling procedure, discuss the convergence conditions and present the results of a convergence testing with the coupled system. The system is used to simulate the impact of climate change; the influence of a baseline scenario and the coupling on the results are highlighted by reference situations. Section 4 outlines the different simulation setups. The results of these simulations are presented in Section 5. Section 6 summarises and concludes.

\section{The Models}

\subsection{GTAP-EF}

In order to assess the systemic general equilibrium effects of climate change on agriculture and land use, we use a multi-region world CGE model called GTAP-EFL. The model is a refinement of the GTAP model, which is a standard CGE static model distributed with the GTAP database of the world economy. ${ }^{2}$ We use the GTAP-E version, modified by Burniaux and Truong [2], which is best suited for the analysis of energy markets and environmental policies. There are two main changes in the basic structure. First, energy factors are separated from the set of intermediate inputs and inserted in a nested level of substitution with capital. This allows for more substitution possibilities. Second, database and model are extended to account for $\mathrm{CO}_{2}$ emissions related to energy consumption. Basically, in the GTAP-EFL model finer industrial and regional aggregation levels are considered (17 sectors and 16 regions, reported in Tables 6 and 7). Furthermore, in GTAP-EFL a different land allocation structure has been modelled for the coupled procedure.

As in all CGE frameworks, the standard GTAP model makes use of the Walrasian perfect competition paradigm to simulate adjustment processes. Industries are modelled through a representative firm, which maximises profits in perfectly competitive markets. The production functions are specified via a series of nested constant elasticity of substitu-

\footnotetext{
${ }^{2}$ For detailed information see Hertel [11], and the technical references and papers available on the GTAP website (www.gtap.org). The website also offers the opportunity to download and modify the model-code in order to gain better insights in its functioning.
}

tion (CES) functions (Fig. 7). Domestic and foreign inputs are not perfect substitutes, according to the so-called Armington assumption, which accounts for product heterogeneity.

A representative consumer in each region receives income, defined as the service value of national primary factors (natural resources, land, labour and capital). Capital and labour are perfectly mobile domestically but immobile internationally. Land (imperfectly mobile) and natural resources are industryspecific. The national income is allocated between aggregate household consumption, public consumption and savings (Fig. 8). The expenditure shares are generally fixed, which amounts to saying that the top level utility function has a Cobb-Douglas specification. Private consumption is split in a series of alternative composite Armington aggregates. The functional specification used at this level is the constant difference in elasticities form: a non-homothetic function, which is used to account for possible differences in income elasticities for the various consumption goods. A money metric measure of economic welfare, the equivalent variation, can be computed from the model output.

In the standard GTAP model, land input is exogenously fixed at the regional level; it is imperfectly substitutable among different crops or land uses. Indeed a transformation function distributes land among five sectors (rice, wheat, other cereals, vegetables and fruits and animals) in response to changes in relative rental rates. Substitutability is equal among all land-use types. The equation that distributes land for any sector is the following:

qoes $_{i, r}=\mathrm{qo}_{r}+\operatorname{ESBV}\left(\mathrm{pm}_{r}-\operatorname{pmes}_{i, r}\right)$

where qoes $_{i, r}$ and pmes $_{i, r}$ are, respectively, the percentage change of land supply and the land market price for sector $i$ in region $r ; \mathrm{qo}_{r}$ and $\mathrm{pm}_{r}$ are respectively, the percentage change of the supply and market price of land in region $r$; ESBV is the elasticity of substitution for primary factors.

Only for the coupled procedure, in the GTAP-EFL model sectoral land allocation becomes exogenous and, consequently, the total land supply change becomes endogenous. The latter is defined as the sum of the land allocation change per sector weighted by the share of the value of purchases of land by firms in sector $i$ on the value of land in region $r$ $\left(\mathrm{SHREL}_{i, r}\right)$, all evaluated at market prices, as follows:

$\mathrm{qo}_{r}=\sum_{i}$ SHREL $_{i, r}$ qoes $_{i, r}$

The market clearing condition for land in each region $r$ is given by the equation:

$\mathrm{qfe}_{i, r}=$ qoes $_{i, r}$

where $\mathrm{qfe}_{i, r}$ is the percentage change of land demand by sector $i$ in region $r$. 


\subsection{KLUM}

The global agricultural land-use model KLUM is designed to link economy and vegetation by reproducing the key dynamics of global crop allocation (see Ronneberger et al. [18] for a detailed description of the model and its evaluation). For this, the maximisation of achievable profit under risk aversion is assumed to be the driving motivation underlying the simulated land-use decisions. That is, a representative landowner is assumed to prefer profitable crops but strives for a portfolio of crops to minimise the risk.

In each spatial unit, the expected profit per hectare, corrected for risk, is calculated and maximised separately to determine the most profitable allocation of different crops on a given amount of total agricultural area (see the Appendix 1 for a mathematical formulation). Additionally, decreasing returns to scale is assumed. Mathematically the sum of these local optima is equivalent to the global optimum, assuring an overall optimal allocation.

As exogenous input parameters, the model takes prices and yields per crop and time step. A cost parameter per crop and a risk aversion factor for each spatial unit are calibrated according to observed data and assumed to be constant over the simulation horizon. As endogenous parameters, the profitability of a crop is determined by its price and yield and risk is quantified by the variance of profits. The main simulation result of the model is the share of allocated land per crop and spatial unit for each time step.

For the present coupling, the output is calculated on country level and we calibrate the sectoral aggregation to four crop aggregates: wheat, rice, other cereal crops and vegetables and fruits so as to match the crop aggregation of GTAP-EFL. A temporal resolution does not apply, as the simulations are comparative static, due to the CGE model.

For the calibration, we use data of the FAOSTAT [7] and World Bank [22] (see Ronneberger et al [18] for details on the calibration process). Yields are specified for each country, prices instead are defined for the 16 different regions equivalent to the regional resolution of GTAP-EFL. Missing data points are adopted from adjacent and/or similar countries of the same region, where similar is defined according to the yield structure of the respective countries. Costs are adjusted for the total amount of agricultural area to guarantee the consistency of results on different scales (see Appendix 2 for further details). For all countries the cost parameters as well as the risk aversion factor are determined in the calibration and are hold constant during all simulations.

\section{The Coupling Procedure}

The coupling of the two models is established by exchanging crop prices and management induced yield changes, as determined by GTAP-EFL, with land allocation changes, as calculated by KLUM. In the coupled framework, the crop allocation in KLUM is determined on country level. Aggregated to the regional resolution, the percentage change of allocated area shares is fed into GTAP-EFL. Based on this, the resulting price and management induced yield changes are calculated by GTAP-EFL and used to update prices and yields in KLUM. Scenarios affecting economic parameters, such as stocks and productivities are applied as exogenous shocks to GTAP-EFL; scenarios concerning environmental changes will be imposed as exogenous yield changes on KLUM. The simulation output consists of the regular output of the two models (see Fig. 1).

Whereas the price changes are part of the regular simulation output of GTAP-EFL, the management-induced yield changes have to be calculated explicitly from the simulation results. In GTAP-EFL, management changes are modelled as the substitution among primary and among intermediate inputs. By using, for instance, more labour than capital or more machines than fertiliser, the per-hectare productivity of the land is changed. We determine the management induced changes in yield $\partial \alpha_{i}$ by adjusting the change $\mathrm{qo}_{i}$ of the total production of crop $i$ by the change in its harvested area qoes $i$, according to:

$\partial \alpha_{i}=\frac{\mathrm{qo}_{i}-\text { qoes }_{i}}{1+\text { qoes }_{i}}$

\subsection{Convergence}

A major challenge of the coupling turned out to be the convergence of the models. To assure the consistency of the coupled system the convergence of the exchanged values to stable and defined quantities needs to be guaranteed. Running the coupled models with their original parameterisation shows that the two systems diverge. Not only land quantities and prices diverge, but also, after the fourth iteration, the GTAPEFL model is unable to find a meaningful economic equilibrium: some variables decrease by more than $100 \%$.

This is the consequence of two main problems. The first results from the different initial land allocations assumed in the two models; the second is due to the general constraint imposed by the structure of the CGE model itself.

The problem of the different initial situations seems like a minor challenge from the conceptual side; however, in combination with the "rigid structure" of the CGE model, it poses a great practical problem. The difficulty originates from the fact that all equilibrium equations in GTAP are formulated in terms of value instead of quantities [11]. During the solving procedure, the changes are distinguished into changes in quantity and changes in price so that the imposition of quantity changes, as calculated in KLUM, is 
Fig. 1 The coupling scheme of KLUM@GTAP

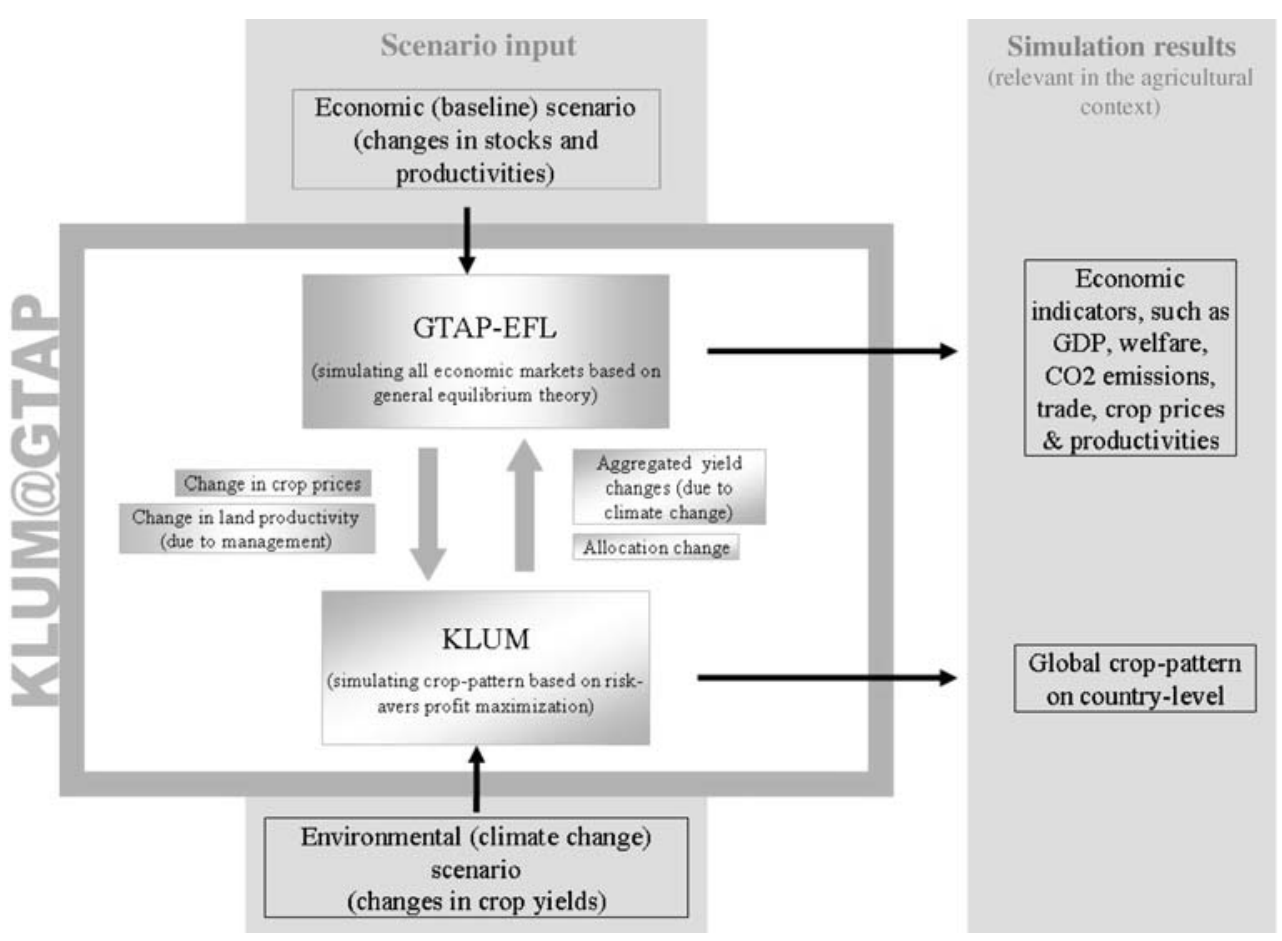

conceptually consistent. But, since prices are set to unity in the benchmark, implicitly, the quantity of land is equalled to the value of land. In the absence of data on the price of land, this makes land quantity data incomparable between GTAP and FAOSTAT [7], to which KLUM is calibrated. This problem is not unique for this coupling but generally occurs when coupling geographic and economic land use models [10]. However, this issue is often elided or ignored. In the following, we track down the effect and consequences to design an adequate solution.

The different initial situation of harvested area in 1997 of GTAP-EFL and KLUM are presented in Table 1. Since the units used in the GTAP model are not specified, we present the allocation as shares of the total crop area of the respective region in the respective model. The global totals per region and crop are given as share of total global cropland in the respective model (stated in the lower right corner of the Table). Obviously, regional and crop specific values as well as the global totals of regions and crops differ tremendously. The global share of land used for wheat production in GATP-EFL is only half of the share used in KLUM. Contrary, vegetables and fruits use twice as much global cropland in GTAP-EFL than in KLUM. Considering that the quantities in GTAP-EFL originally represent the monetary value of cropland this distortion is understandable. But for the coupled framework this means that e.g. small absolute changes in the area share of vegetables and fruits of KLUM translate into large absolute changes in GTAP-EFL. Also, the shares of total area used in the different regions differ notably. Whereas in GTAP-EFL, large shares of total global cropland are situated in Western Europe, South Asia and the USA, only the largest areas of cropland in KLUM is also harvested in South Asia; other major shares can be found in China, Subsaharan Africa and the Former Soviet Union. These differences are of less importance in the KLUM model where each spatial unit is optimised independently. In GTAP-EFL, however, e.g. the trade structure is impacted by the regional distribution of resources. Thus, relatively small changes of aggregated absolute allocation in e.g. Western Europe can cause large shocks in GTAP-EFL.

In principle, the optimal solution would be to recalibrate the GTAP-EFL model according to the observed land allocation consistent with KLUM. However, this would entail a complete recalibration of all model parameters in order to re-establish a new initial stable equilibrium consistent with the entire observed situation of 1997. This would be a major task due to the 'rigid structure' of the model, and it would be arbitrary without land price data.

Another solution would be to introduce a land market into KLUM to transform the areas to values, hoping to reach a comparable consistency among the models. But this would imply remodelling details that are already simulated in GTAP and again, without data on land prices a comparison of the results to insure constancy between the models would be arbitrary. Thus, this would just shift the problem of initial inconsistencies and make it less traceable.

The "structural rigidity" of CGE models follows from their theoretical structure. Economic development is simulated by equating all markets over space and time, assuming that a general economic equilibrium is the best guess 
Table 1 Initial shares of harvested areas in GTAP and KLUM

\begin{tabular}{|c|c|c|c|c|c|c|c|c|c|c|}
\hline \multirow{2}{*}{$\frac{\text { Crop }}{\text { Region }}$} & \multicolumn{2}{|l|}{ Rice } & \multicolumn{2}{|l|}{ Wheat } & \multicolumn{2}{|c|}{ Cereal crops } & \multicolumn{2}{|c|}{ Vegies and fruits } & \multicolumn{2}{|l|}{ Total } \\
\hline & GTAP & KLUM & GTAP & KLUM & GTAP & KLUM & GTAP & KLUM & GTAP & KLUM \\
\hline USA & 0.011 & 0.017 & 0.172 & 0.336 & 0.546 & 0.495 & 0.271 & 0.153 & 0.147 & 0.078 \\
\hline CAN & 0.000 & 0.000 & 0.336 & 0.447 & 0.244 & 0.305 & 0.419 & 0.249 & 0.007 & 0.026 \\
\hline WEU & 0.003 & 0.007 & 0.323 & 0.302 & 0.345 & 0.374 & 0.329 & 0.317 & 0.196 & 0.060 \\
\hline JPK & 0.369 & 0.573 & 0.005 & 0.030 & 0.146 & 0.057 & 0.480 & 0.340 & 0.066 & 0.005 \\
\hline ANZ & 0.016 & 0.008 & 0.210 & 0.533 & 0.293 & 0.353 & 0.480 & 0.106 & 0.006 & 0.020 \\
\hline EEU & 0.004 & 0.001 & 0.121 & 0.273 & 0.295 & 0.480 & 0.580 & 0.246 & 0.016 & 0.030 \\
\hline FSU & 0.182 & 0.005 & 0.068 & 0.420 & 0.106 & 0.370 & 0.644 & 0.206 & 0.011 & 0.113 \\
\hline MDE & 0.030 & 0.018 & 0.116 & 0.477 & 0.134 & 0.269 & 0.720 & 0.236 & 0.012 & 0.042 \\
\hline CAM & 0.025 & 0.023 & 0.038 & 0.047 & 0.466 & 0.703 & 0.470 & 0.227 & 0.040 & 0.017 \\
\hline SAM & 0.042 & 0.086 & 0.074 & 0.145 & 0.230 & 0.392 & 0.654 & 0.377 & 0.075 & 0.060 \\
\hline SAS & 0.243 & 0.324 & 0.085 & 0.208 & 0.166 & 0.213 & 0.506 & 0.255 & 0.156 & 0.187 \\
\hline SEA & 0.350 & 0.564 & 0.000 & 0.000 & 0.148 & 0.227 & 0.502 & 0.209 & 0.108 & 0.075 \\
\hline $\mathrm{CHI}$ & 0.166 & 0.225 & 0.058 & 0.209 & 0.121 & 0.239 & 0.655 & 0.326 & 0.096 & 0.151 \\
\hline NAF & 0.001 & 0.047 & 0.357 & 0.379 & 0.184 & 0.306 & 0.458 & 0.268 & 0.008 & 0.015 \\
\hline SSA & 0.171 & 0.064 & 0.023 & 0.019 & 0.427 & 0.587 & 0.379 & 0.330 & 0.016 & 0.115 \\
\hline ROW & 0.127 & 0.083 & 0.082 & 0.000 & 0.246 & 0.163 & 0.545 & 0.754 & 0.039 & 0.004 \\
\hline Total & 0.133 & 0.157 & 0.129 & 0.231 & 0.276 & 0.346 & 0.462 & 0.266 & 965573 & 268948 \\
\hline
\end{tabular}

The emphasised totals are relative to total global cropland (as quoted in the lower right corner, KLUM's quantity is given in 1,000 ha). The region specific crop shares relate to total cropland in the respective region.

possible to describe economic patterns and to project their development for different scenarios. All markets are assumed to clear, and the equilibrium is assumed to be unique and globally stable. Guaranteeing these assumptions while assuring applicability to a wide range of economies and policy simulation implies that a number of regularity conditions and functional specifications need to be imposed. Accordingly, such models generally may find difficulties in producing sound economic results in the presence of huge perturbations in the calibration parameters or even in the values of exogenous variables characterising their initial equilibrium. We replace GTAP endogenous land allocation mechanism with exogenous information provided by the land use model. This new allocation is not driven by optimal behaviour consistent with the GTAP framework and can thus distort the system in such a way that convergence can no longer be guaranteed. This is also the reason why we use GTAP with endogenous land allocation to establish the first instance of the baseline benchmark. Combining the large shocks of the baseline scenario with the exogenous land allocation mechanism determined by KLUM would overstrain the solving algorithm of GTAP-EFL.

To assure convergence, the land-use model would need to be formulated as a consistent part of the CGE-assuring all markets to be in equilibrium. This, however, would be difficult to combine with the intention of replacing the purely economic allocation decisions by a more flexible model, which takes into account the biophysical aspects of land-use decisions on a finer spatial resolution.
Thus, for the moment - to lower the influence of the initial situation on the one hand and to promote convergence on the other hand-we simply decrease the responsiveness of GTAP-EFL to changes in land allocation. The key parameter governing this is the sectoral elasticity of substitution among primary factors ESBV (compare Eq. 1). This parameter describes the ease with which the primary factors (land, labour and capital) can be replaced by one another for the production of the value-added (see e.g. [11] for more details). To manipulate this parameter to ensure convergence might seem arbitrary or even dangerous. Increasing ESBV certainly is an ad hoc technical solution aimed at decreasing price oscillation in GTAP and improving the convergence process. However, scientific justifications can be adduced: firstly, the values for these elasticities are 'low' in the original GTAP model (Hertel 2006 personal communication); secondly, it is commonly accepted that long-term elasticities tend to be higher than short term ones. This typically applies to demand elasticities to prices, which in a CGE framework translates to increasing substitution elasticities. As our simulations are performed to a reference year quite far in the future, the expedient can be reasonable.

In a set of sensitivity tests, we verified that in response to a land productivity or quantity shock, in the "tripled elasticity"GTAP, price changes are indeed the $30 \%$ to the $70 \%$ smaller than in the original one. Real variable behaviour is mixed. Gross domestic product (GDP), for instance, does not differ qualitatively between the two simulations but only quantitatively in a range of the $0.2-13 \%$, depending on the region. 


\subsection{Convergence Test}

The convergence test aims to investigate the convergence of the coupled system by initially shocking the system to, then, audit its convergence behaviour in succeeding undisturbed loops. For this, the productivity of land for all crops in all regions in GTAP-EFL is shocked with a uniform increase of $2 \%{ }^{3}$ Then, a normal coupling loop is started: resulting price and yield changes (including the original land productivity changes) are applied to KLUM. The land allocation changes as calculated by KLUM are appended to the original productivity changes and re-imposed on GTAP-EFL. This loop is repeated for ten iterations.

In case of divergence, we increase the ESBV in GTAPEFL and rerun the procedure.

\subsubsection{Results of the Convergence Test}

A first set of simulations (not presented here) revealed that price, yield and area-share changes for the region Rest of the world diverged quickly and distorted the performance of the complete system, preventing the existence of a common equilibrium. This region encompasses the 'remaining' countries not included in any of the other regions. The composition slightly differs between the two models on the one hand and this region is of minor importance on the other hand. Thus we completely exclude this region from the coupling experiment. No data is exchanged between KLUM and GTAP-EFL for this region in any of the presented simulations.

Figure 2 depicts the iteration process for doubled and tripled elasticity for North Africa and South Asia. We chose these regions as representatives, because they best show all the dominant behaviour observed also in the other regions. For doubled elasticity, a strong divergence of the iterating values can be observed in both regions for all crops. Only the results for wheat in North Africa reveals converging behaviour, as can be seen from the markers tightly clustered around the mean value. This corresponds to the initial differences in land allocation: in both regions for nearly all crops, the initial area shares for the different crops differ considerably between the two models (Table 1); only wheat in North Africa shows similar shares in both models. Generally, the divergence is much stronger in South Asia than in North Africa. This indicates that the influence of trade emphasises the observed changes: according to GTAP-EFL South Asia holds about a sixth of total global cropland, making it one of the potentially largest crop producers. North Africa instead is

\footnotetext{
${ }^{3}$ The chosen quantity of change is arbitrary. Indeed any perturbation to the initial GTAP equilibrium would have originated a set of changes in crops prices that could have been used as the first input in KLUM to start the convergence test.
}

one of the smallest producers in term of harvested area (compare Table 1). Of course, the described trends cannot be mapped linearly to all regions and crops. But, the general tendency is visible throughout the results.

Convergence is clearly improved with tripled elasticity. Whereas the spread of exchanged values for the doubleelasticity simulations is increasing with increasing iteration number, the data points of the tripled-elasticity simulations are tightly clustered, approaching the marked mean (the empty red marker) with proceeding iteration step. An investigation of the relative changes of exchanged values (not shown here) underpins the impression given in the presented graphs, ensuring that the visual impression is not governed by the different extent of absolute values (generally larger for doubled than tripled elasticity). With tripled elasticity the standard deviation of the last four iterations is less than $5 \%$ of the respective mean value for $85 \%$ of all exchanged quantities, confirming the observed convergence. Thus the following simulations are performed with an elasticity of $E S B V \cong 0.711$.

\section{Experimental Design}

KLUM@GTAP was developed to assess the impact of climate change on agricultural production and the implications for economic development. We perform a set of illustrative future simulations to demonstrate the capability of the coupled framework to provide plausible and robust future simulations despite the above discussed convergence issue on the one hand; and on the other hand to evaluate the effect of the coupling on the results.

To simulate the effect of climate change we first apply an economic baseline scenario, which describes a possible projection of the world in 2050 without climate change (see Appendix 3 for details). On top of that, we impose estimates of climate change impacts so as to portray the situation in 2050 with climate change; the respective simulation is called $c c 2050$.

The convergence of the system is highly influenced by the 'starting point'. Thus, to clarify the impacts of the baseline on our climate change assessment and to confirm the stability of the coupled system, we perform also a reference simulation: the climate change scenario is directly applied onto the 1997 benchmark; this simulation is referred to as $c c 1997$.

The effect of the coupling on the results is highlighted, by estimating the climate change impacts also with the uncoupled models (referred to as the uncoupled simulations). In both models, we use the benchmark equilibrium 2050 of the baseline simulation as the starting point and apply the climate change scenario. The GTAP-EFL model is used with endogenous land allocation. Country-level 
Fig. 2 Results of the convergence test for North Africa and South Asia: The plots depict the space spanned by the percentage changes in price, yield and areashare. Round markers: results under doubled elasticity; Square markers: results under tripled elasticity. With proceeding iteration size and darkness of the markers gradually increase.

The empty red marker marks the mean value of the last four iterations; the length of the axes crossing at this point mark the total spread of all iteration states. The perspective of the coordinate system differs among plots to allow an optimal view on the respective data
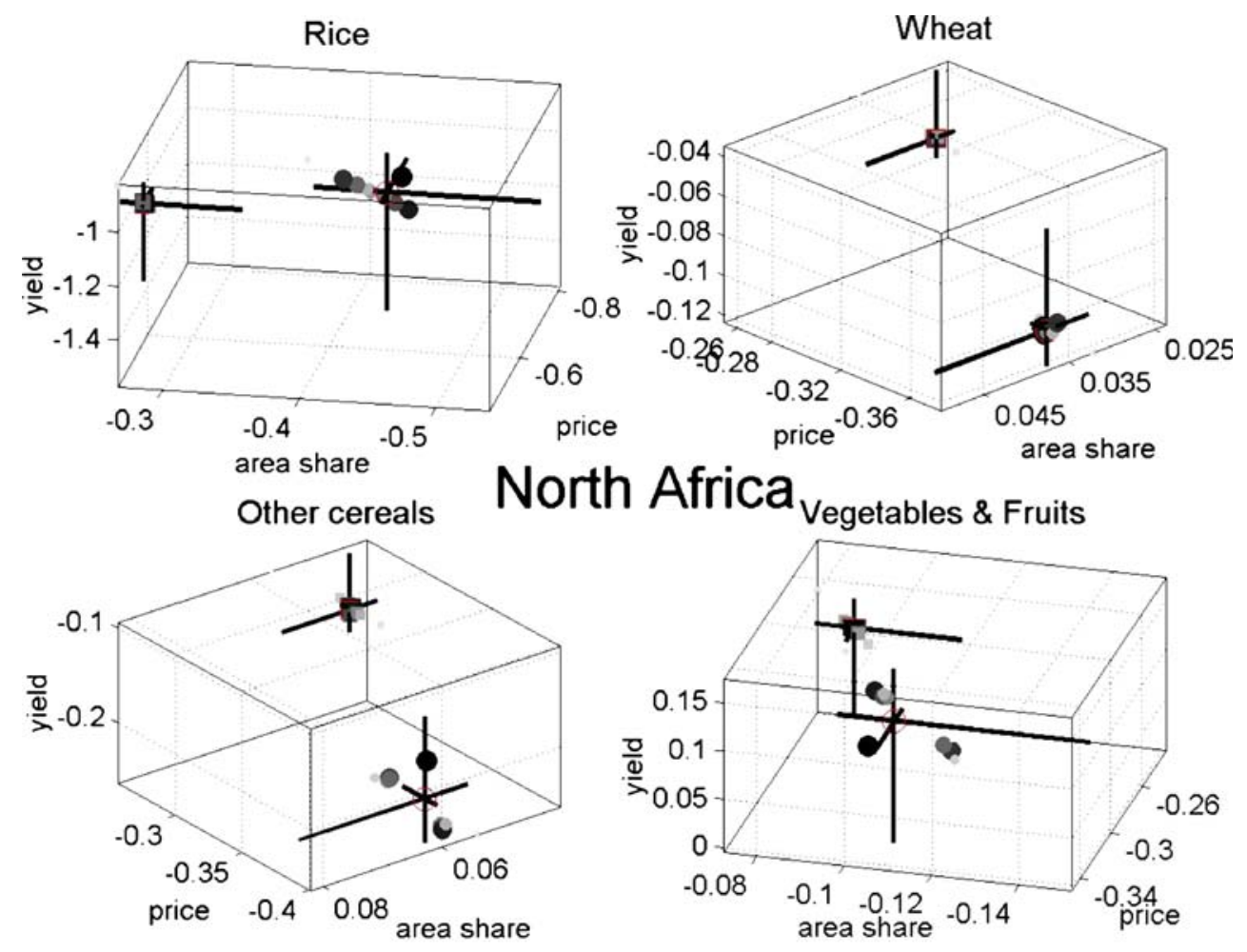

Africa ${ }_{\text {Vegetables \& Fruits }}$
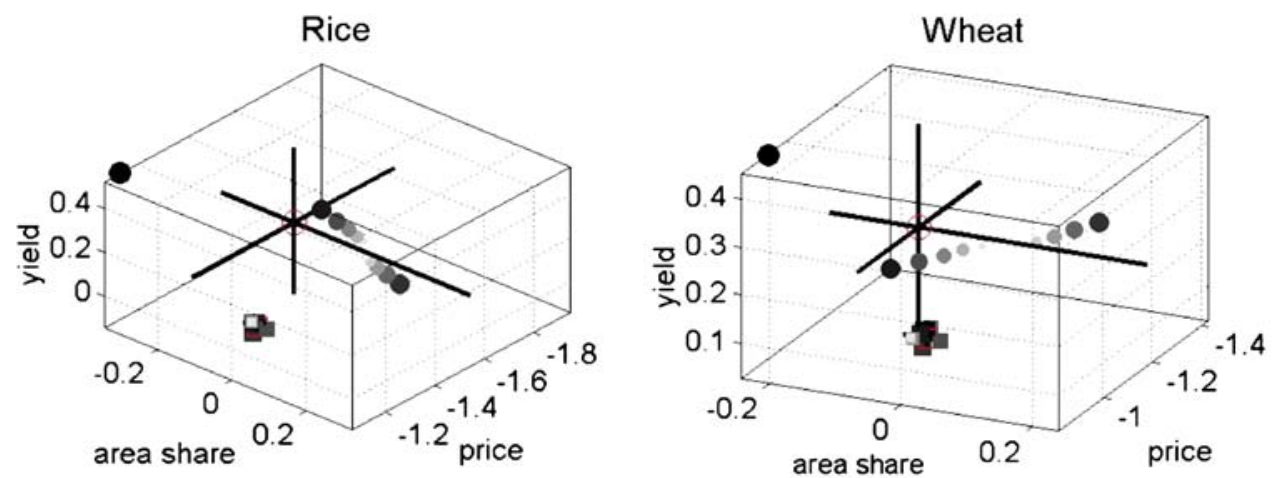

Other cereals South Asia Vegetables \& Fruits
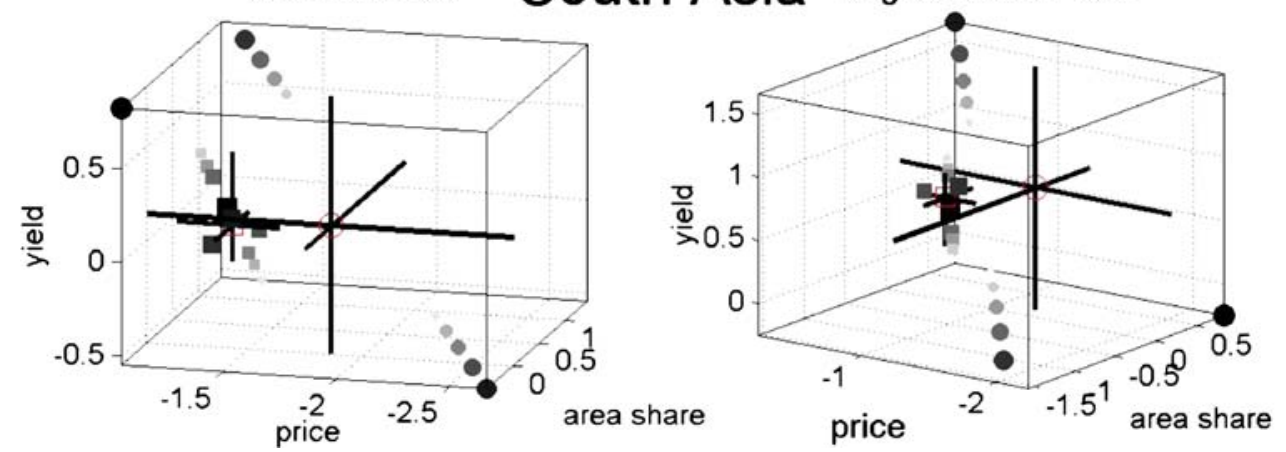
Table 2 Overview over the different simulations

\begin{tabular}{lllll}
\hline & Model & Benchmark & Imposed changes & $\begin{array}{l}\text { Starting } \\
\text { point }\end{array}$ \\
\hline Baseline & KLUM@GTAP & 1997 & Baseline scenario (see Table 8) & GTAP-EFL \\
cc 2050 & KLUM@GTAP & 2050 & Climate change scenario (see Fig. 9) & KLUM \\
cc 1997 & KLUM@GTAP & 1997 & Climate change scenario (see Fig. 9) & KLUM \\
Uncoupled & GTAP-EFL & 2050 & Climate induced yield changes aggregated by KLUM & GTAP-EFL \\
& KLUM & 2050 & Climate change scenario (see Fig. 9) +price and management & KLUM \\
& & & induced yield changes of uncoupled GTAP-EFL simulation
\end{tabular}

Benchmark initial situation of the model, starting point model on which the initial change, described in column imposed changes is imposed

allocation shares of the KLUM benchmark 2050 are used to aggregate the yield changes of the climate change scenario to the regional level. KLUM standalone is driven by the climate change scenario and exogenous price and management changes according to the uncoupled GTAP-EFL. Like this, the KLUM model describes a partial equilibrium situation.

The different scenarios are summarised in Table 2. More detail on the explicit assumptions, the used data and the performed iterations are given in Appendix 3.

\section{Results}

The simulation results can be divided into general changes of the economy and those directly affecting the coupled crop sector. As general economic changes we study changes in GDP, welfare, $\mathrm{CO} 2$ emissions and trade. Changes in the crop sector are described by changes in crop prices and production and in the allocation of cropland.

The focus of this paper is on the coupling of the models; thus, we use the simulation results to illustrate the general

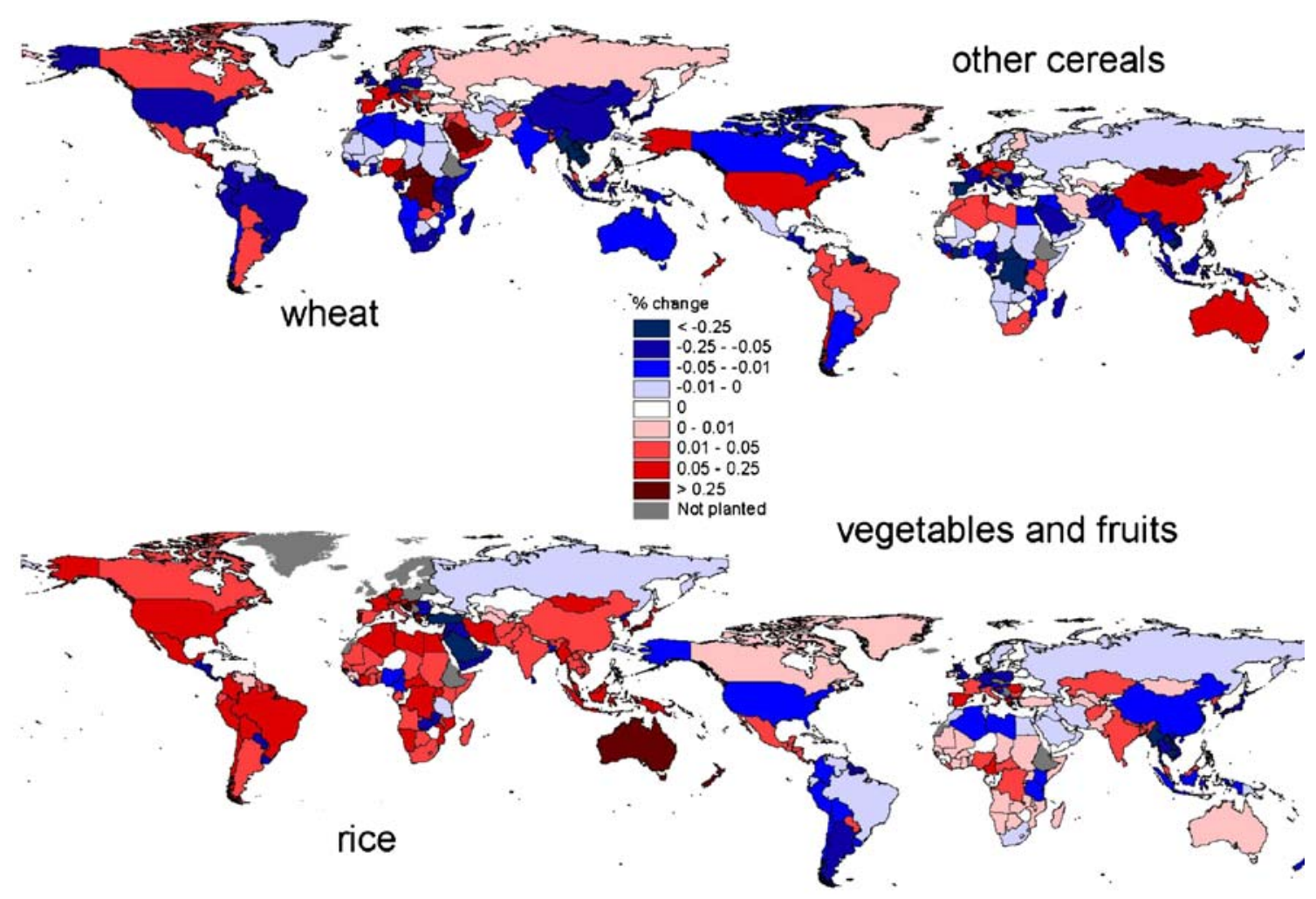

Fig. 3 Climate change impacts on cropland allocation: Percentage changes in cropland allocation in the climate change scenario relative to 2050 (cc 2050) according to KLUM@GTAP. In grey countries, the crop is either not planted or no data is present 


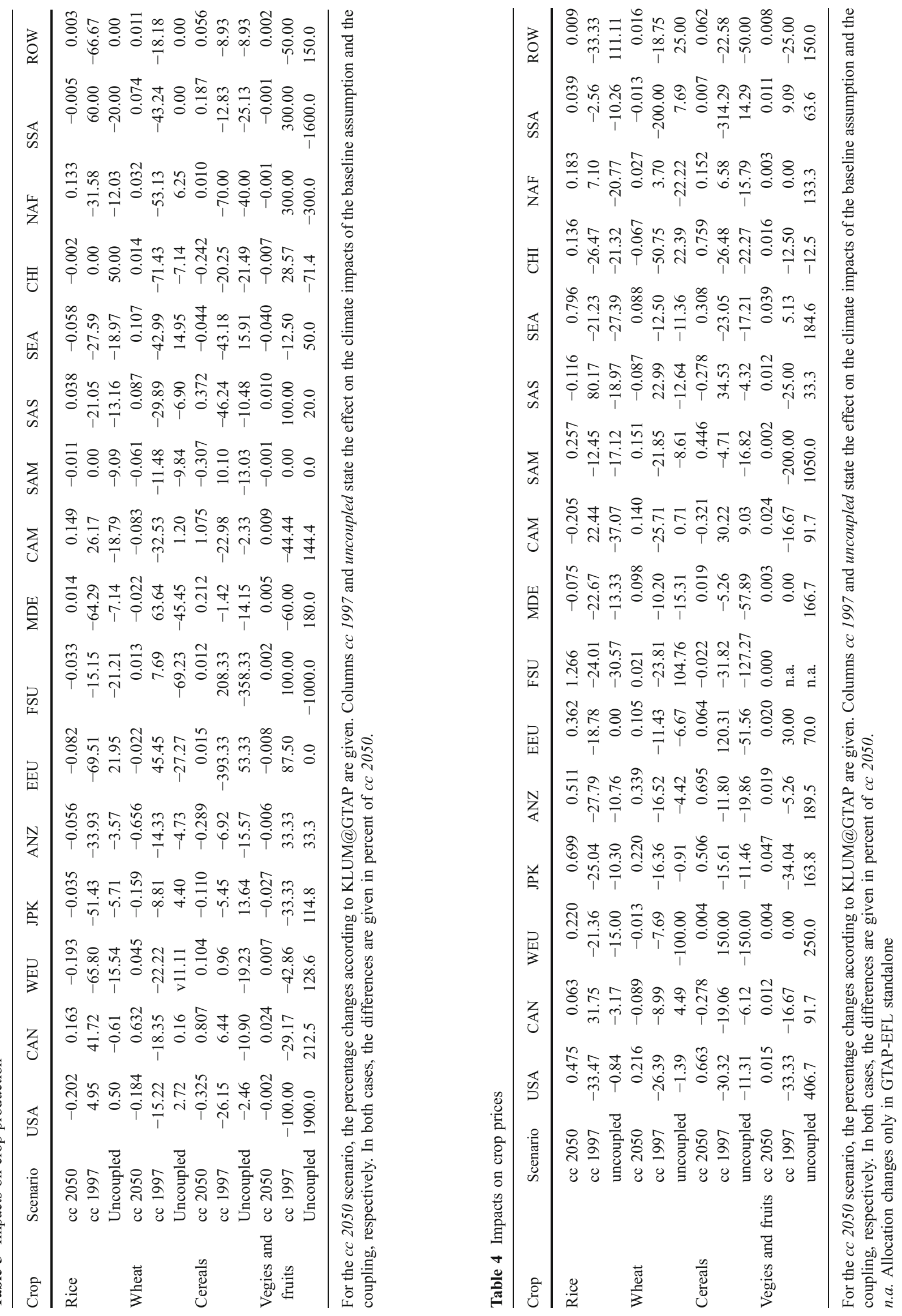


capability of the model to simulate plausible futures under climate change, their stability and the effect of the coupling. Therefore, in the description of the results, we focus on the results of the $c c 2050$ simulation and their sensitivity to the starting point ( $c c 2050$ versus $c c$ 1997) and to the coupling (cc2050 versus uncoupled).

\subsection{Climate Change in 2050 (cc 2050)}

The absolute extent of climate impacts are rather small due to the comparably small climate-induced yield changes (see Appendix 3). We thus concentrate on the trends and intercomparison of changes, rather than on the absolute extent.

The impact of a changing climate on land allocation and the crop sector, according to KLUM@GTAP are shown in Fig. 3 and Tables 3 and 4. We observe increases in the area share and price for rice production in nearly all countries and regions; production instead is decreasing. Obviously, the losses in yield are counteracted by an increase of the area share, increasing the prices. Also for several other regions and crops, such as other cereals in China and USA or wheat in South America, yield losses are compensated by area gains and prices rise. Only for vegetables and fruits, this pattern is not observable; as the yields are unaffected in our climate change scenario, this is not surprising. In general, for the majority of regions, the production of rice and vegetables and fruits is decreasing, whereas for wheat and other cereals, more regions increase the production (Table 3); price changes show an opposite pattern. The cropland changes of wheat and other cereals reveal an interesting scheme: they are of opposed signs in nearly all countries. As we do not observe the same pattern in the imposed yield changes, this can be interpreted as direct competition of these crops. The similar price, allocation and yield structure of wheat and other cereals makes their relative allocation changes sensitive to small perturbations: according to minor price and yield changes either one or the other is preferred in production.

The crop production changes by and large explain the pattern of losses and gains observed for GDP and welfare (Fig. 4, red bars). Losses in GDP and welfare are present in most but not all the regions. We observe strong gains in Central America and South Asia and smaller gains in Subsaharan Africa, Canada and Western Europe: all regions where also for crop production the increases prevail. Generally, $\mathrm{CO}_{2}$ emissions change in accordance with GDP. Only the USA, the Former Soviet Union and Eastern Europe are notable exceptions. In these regions, the 'composition' effect dominates the 'size' effect; that is, in terms of emissions, the change in the production mix to more carbon intensive goods dominates the total loss in production. Also, the trade balance reveals a clear connection to GDP and welfare changes: for nearly all regions, gains in GDP and welfare are accompanied by losses in the trade balance and vice versa. In terms of trade, WEU shows the highest losses.

\subsection{The Effect of the Baseline on the Climate Change Simulation (cc2050 Versus cc 1997)}

We assess the effect of the baseline scenario on the estimations of climate impacts by comparing results of scenario $c c 1997$ (where the climate scenarios is imposed on the current situation) to those of scenario $c c 2050$ (where
Fig. 4 Climate change impacts on the economy: Changes in economic indicators according to the different climate change simulations. The $c c 2050$ and $c c$ 1997 simulations are performed with the coupled system. The uncoupled simulation is performed with GTAP-EFL standalone
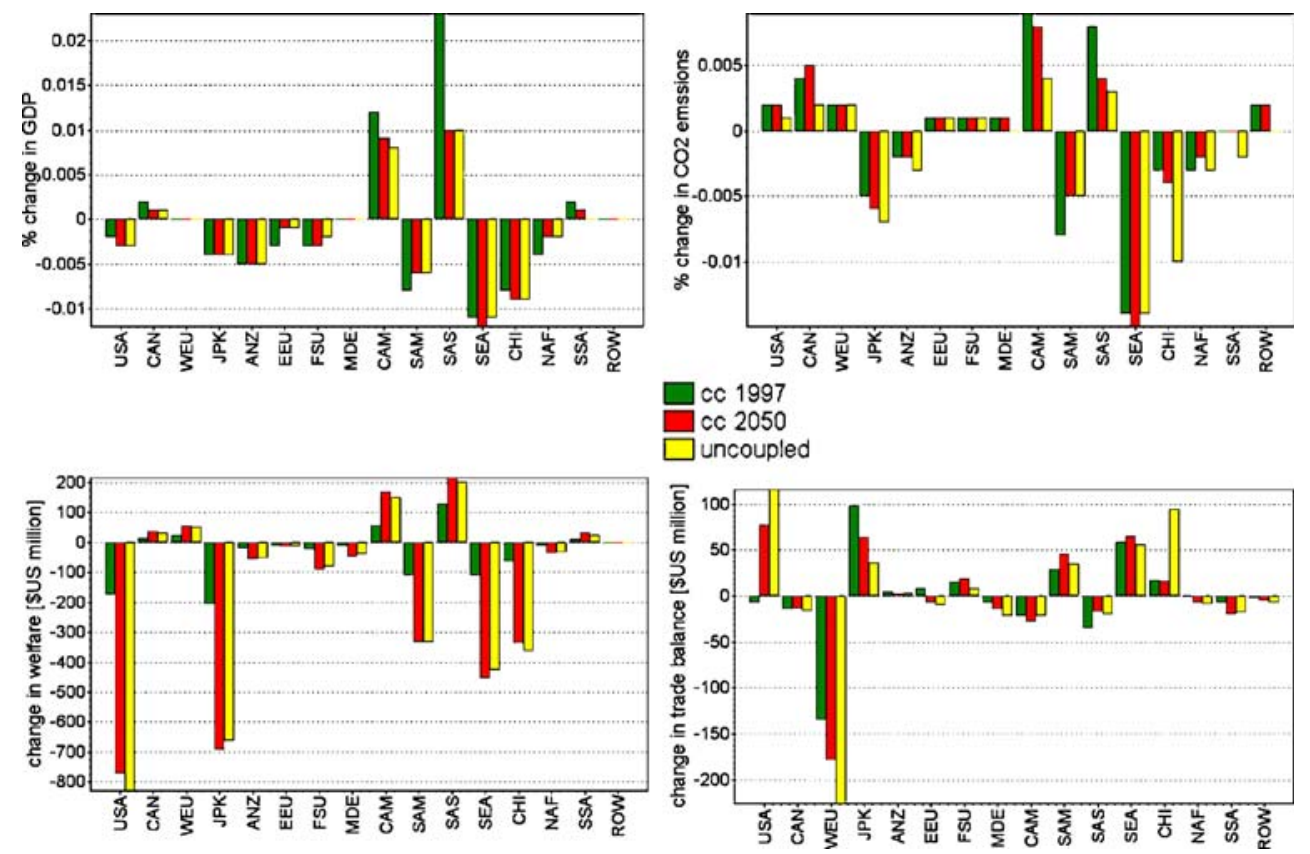


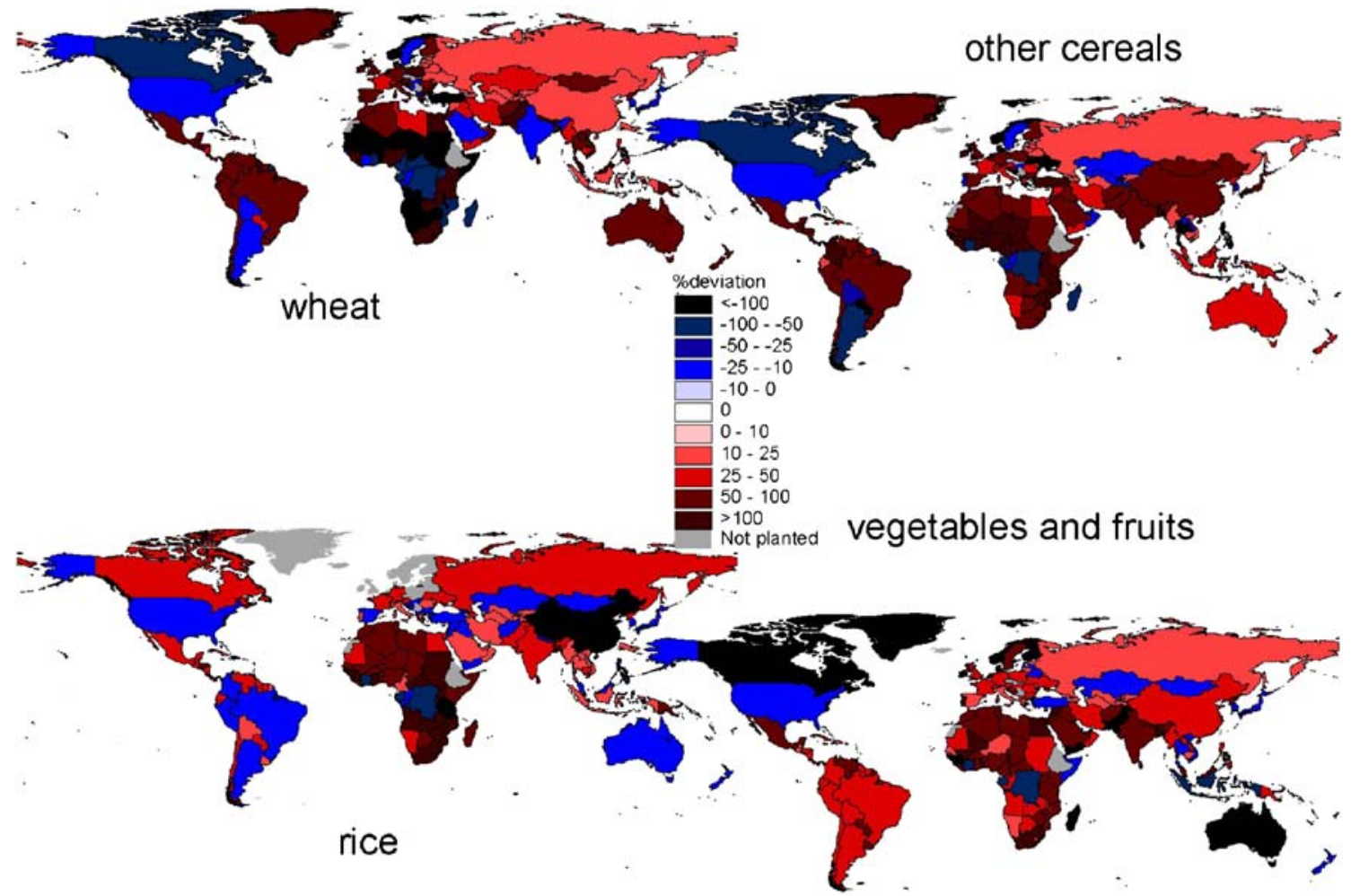

Fig. 5 Effect of the baseline scenario on simulated climate impacts: Climate impacts relative to the current situation (cc 1997) are compared to those estimated relative to the baseline (cc 2050). The

the climate change scenario is applied to the baseline benchmark of 2050). Figure 5 shows that excluding the baseline generally leads to an increase in allocation changes. Contrary, crop prices and production changes exceed the climate impacts with the baseline in the order of some $10 \%$ (Tables 3 and 4 ). This reflects the way land is treated in the CGE. In the baseline scenario, the productivity of land increases, causing an increase of land value. Therefore, in the climate simulations which start from the differences are expressed in percentage of the latter. In grey countries, the crop is either not planted or no data is present

baseline, the land quantities increase as well due to the unity prices in the benchmark. An introduced percentage change in land, hence, translates to a much larger absolute change in the 2050 benchmark situation than in the 1997 benchmark situation. Principally, however, the pattern of changes in crop prices, productions and land allocation is conserved, indicating the stability of the coupled system.

The same is true for the economic changes of the $c c$ 1997 simulation (green bars in Fig. 4). For almost all
Table 5 Effect of the coupling on climate change impacts on cropland allocation
The results of the GTAP-EFL standalone (uncoupled) and the KLUM@GTAP simulation (cc 2050) are compared; differences are expressed in percent of the latter n.a. Allocation changes only in GTAP-EFL standalone

\begin{tabular}{lllll}
\hline Percent (\%) & Rice & Wheat & $\begin{array}{l}\text { Cereal } \\
\text { crops }\end{array}$ & $\begin{array}{l}\text { Vegies and } \\
\text { fruits }\end{array}$ \\
\hline USA & & & 137.23 & 457.89 \\
CAN & -7.52 & 6.30 & 1500.00 & -1500.00 \\
WEU & 7.69 & 172.73 & -105.26 & -97.22 \\
JPK & 301.10 & -123.53 & -860.00 & 177.39 \\
ANZ & 138.82 & 17.05 & 768.00 & 4233.33 \\
EEU & 40.79 & -105.56 & -140.00 & -10.00 \\
FSU & 10.55 & 107.69 & 16800.00 & n.a. \\
MDE & n.a. & n.a. & -728.57 & -1700.00 \\
CAM & 125.00 & 2316.67 & -372.73 & -218.75 \\
SAM & -3100.00 & -27.66 & 1826.67 & 220.00 \\
SAS & 422.22 & -376.47 & 205.71 & -4.55 \\
SEA & -559.09 & 194.44 & -74.07 & 40.63 \\
\hline
\end{tabular}


regions and indicators, the sign as well as the relative extent of the changes are similar to those projected relative to the baseline (red bars). The trade balance in Eastern Europe and the USA are the only exceptions; in Eastern Europe, the impact on the trade balance is very small in each case; in the baseline scenario, the USA loses its competitive advantage in agriculture to other regions, which explains the reversal in sign. Evidently, the changes in welfare are much smaller, if no baseline is applied. This, however, only reflects the initial welfare difference of the 1997 and the 2050 benchmark as welfare changes are expressed in US dollar equivalents rather the percentages. Qualitatively, the welfare impacts are very similar.

\subsection{The Effect of the Coupling on the Climate Change Simulation (cc2050 Versus Uncoupled)}

Also, for the coupling, we assess the effect on the results by studying differences of uncoupled to coupled simulation. GTAP-EFL standalone is driven only by the regionally aggregated climate-induced yield changes; land allocation is endogenous. KLUM standalone is driven by the climate change scenario and crop prices and management-induced yield changes of GTAP-EFL standalone; feedbacks, though, are excluded.

\subsubsection{GTAP-EFL Standalone}

The resulting land allocation changes of GTAP-EFL standalone differ from the results of the coupled system simulation by several hundred up to thousand percent (shown in Table 5); in some cases, even the signs differ. We see the highest differences for other cereals and rice, indicating that greater yield changes emphasise the gap between coupled and uncoupled simulation. Also, crop prices and productions differ notably between the coupled and the uncoupled simulation: differences are in the order of some ten up to several hundred percent. For rice GTAPEFL standalone underestimates most of the changes in prices and productions, whereas for vegetables and fruits overestimations prevail. Some few estimates even change sign due to the coupling. Whereas for the coupled simulation, e.g. prices of cereal crops increase in Western Europe and fall in the Former Soviet Union; they show the opposite behaviour in the uncoupled scenario. The largest differences between the simulations can be seen for vegetables and fruits. Note that vegetables and fruits are assumed not be affected by climate change directly; these changes result from the indirect impacts on allocation. Even though the region Rest of the world was excluded from the coupling, we reveal large differences between the coupled

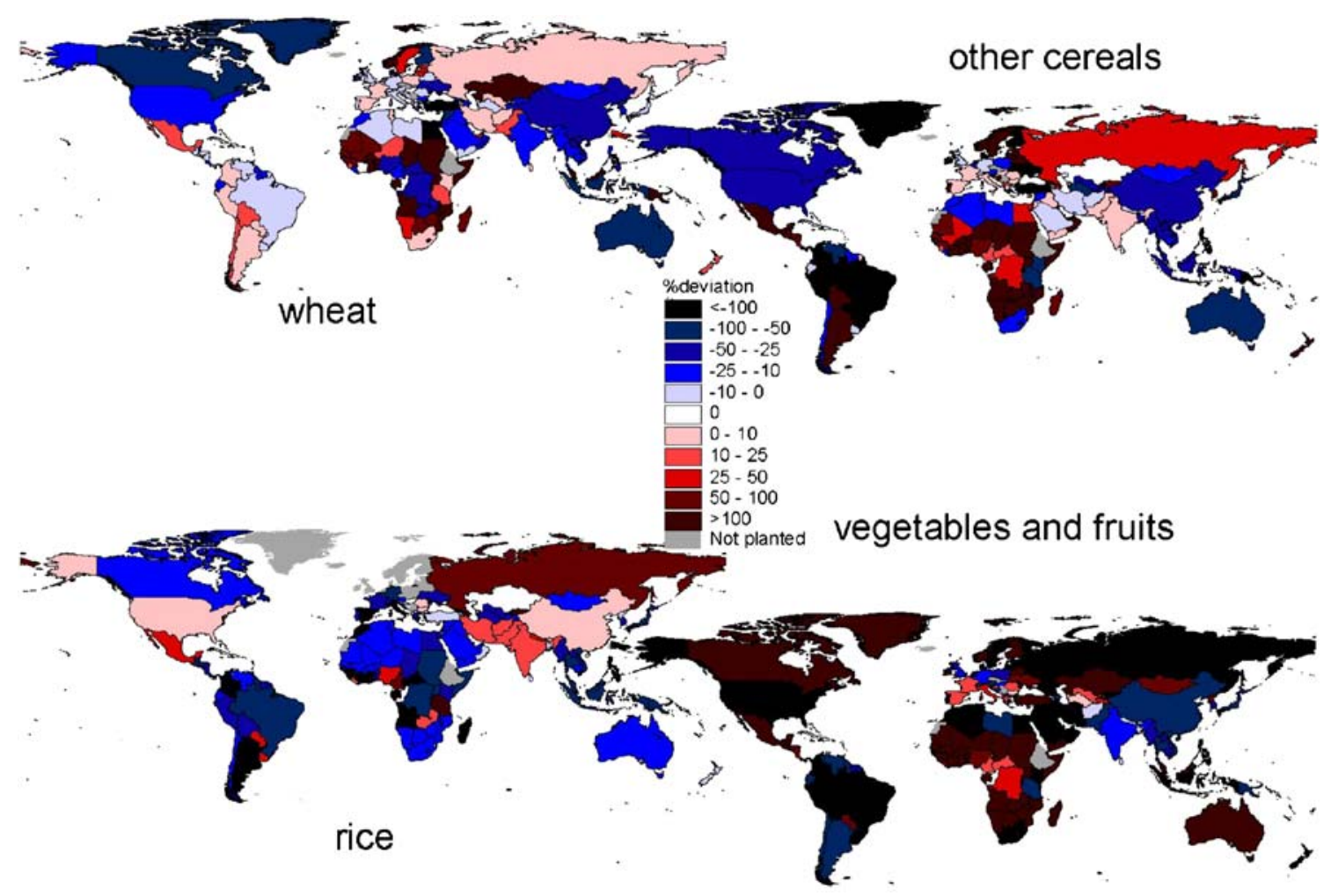

Fig. 6 Effect of the coupling on simulated climate impacts: Climate impacts according to KLUM standalone (uncoupled) are compared to those of KLUM@GTAP (cc 2050). The differences are expressed in percentage of the latter. In grey countries, the crop is either not planted or no data is present 
and the uncoupled simulation for the price changes in this region. These are purely indirect effects.

The economic changes in GTAP-EFL standalone (Fig. 4, yellow bars) differ from those in KLUM@GTAP in extent but not in sign. The differences are generally low; only for China, they reach up to several hundred percent; again, the effect is strongest on the trade balance. The low differences reflect the general low responsiveness of these indicators in GTAP-EFL to land allocation changes, which is even damped in our simulations by the increased elasticity.

\subsubsection{KLUM Standalone}

The percentage differences of land allocation changes in KLUM standalone to KLUM@GTAP are in the range of \pm $10-100 \%$ reaching up to several hundred percent (Fig. 6). We see even a change of sign in some countries, especially for the case of vegetables and fruits; generally the differences for vegetables and fruits are largest and mainly positive. Again, these changes are solely triggered by price and management changes or indirect allocation effects. Obviously, these factors are strongly impacted by the coupling procedure: in the general equilibrium setting of the coupled simulation these factors are dampened by inter sectoral effects and trade. We see that KLUM standalone tends to overestimate decreases and underestimate increases of area changes in rice production; the total area share of rice is, thus, underestimated. The pattern of deviations for wheat and other cereals are rather similar but with generally stronger deviations for other cereals. This underpins the observation that the coupling effect grows stronger with larger scenario changes.

\section{Summary and Conclusion}

We present in this paper the coupling of a global computable general equilibrium model with a global agricultural land-use model in order to consistently assess the integrated impacts of climate change on global cropland allocation and the implication for economic development. The linking of the models is established by exogenising the land allocation mechanism of GTAP-EFL and by replacing it with the dynamic allocation module KLUM. Price and management changes, according to GTAP-EFL and country-specific yield values, drive KLUM; regionally aggregated area changes determined by KLUM are used to update the cropland shares in GTAP-EFL. This intimate link allows a direct and spatially more explicit projection of biophysical aspects of land-use decisions onto economic crop production; the effects of economic trade and production decisions are projected back onto country specific crop patterns. By this, the framework provides a consistent picture of the economy and of agricultural land cover.

In the first part of the paper, we investigated the convergence behaviour of the coupled system. We identified as key problem of an ensured convergence the initial situation of land allocation in GTAP-EFL combined with the 'rigid structure' of the model. The initial cropland shares in GTAP-EFL are given in 'value added of production'. But due to the assumptions of unity prices in the benchmark, the same numbers are treated as quantity values during the simulations and are updated by the changes determined by KLUM. KLUM, on the other hand, calculates allocation changes based on observed area shares of FAOSTAT [7], which differ tremendously from the values used in GTAP. This difference causes a distortion of the introduced changes and can lead to divergence. As a workaround, we lowered the responsiveness of the CGE to the introduced cropland share changes by increasing the sectoral elasticity of substitution for primary factors. By means of a convergence test with the coupled framework, we were able to show a clear improvement of the convergence behaviour due to this tactic. Moreover, the test confirmed the connection of the discriminative initial situations and the convergence behaviour. With a tripled elasticity, convergence was reached in all regions for all crops. The change in results (which was confirmed by reference simulations to be minimal) caused by the new elasticity is acceptable considering the general uncertainties underlying the values of elasticities [11]. Moreover, the initial elasticity was rather low (Hertel 2006, personal communication). The tripled elasticity was used in the succeeding simulations and convergence was audited for the performed experiments.

However, a general guarantee of convergence for the coupled system cannot be established by means of the convergence test. The complex system of the CGE is distorted by the inclusion of the land-use model that is not formulated consistently with the general equilibrium framework. Above this, the offset caused by setting land values to quantities in the benchmark is even enhanced when land becomes scarce and thus more valuable, as in our baseline scenario. One way to solve the convergence problem is to use CES production functions in KLUM and to take intermediate inputs to agriculture from GTAP-EFL as well. This would tighten the interaction between GTAP-EFL and KLUM. Yet, it would also imply that KLUM can no longer be run as a standalone model, hampering model validation 
and the coupling to biophysical models at a finer geographical resolution.

In the second part of the paper, we illustrate that plausible estimations of climate change impacts are still feasible under the uncertainties mentioned afore. Crop production changes according to the pattern of induced yield changes. Yield losses are often compensated by area increases, causing prices to rise. A negative impact of climate change for nearly all regions in terms of GDP and welfare was revealed. Only Central America and South Asia show strong gains and some smaller gains are revealed in Subsaharan Africa, Canada and Western Europe. This also reflects the pattern of induced yield changes. The remaining economic indicators follow the pattern of GDP and welfare. Emission and crop production changes are in line with GDP and welfare changes; trade balance and crop price changes are of opposite sign.

The convergence of the system is highly influenced by the starting point. The effect of the baseline scenario on the results as well as the stability of the coupled system was, thus, studied by a reference scenario in which the climate impacts were directly introduced to the current situation. The baseline assumptions influence the extent but not the general pattern of the results, reflecting the robustness of the model. Crop prices and production changes are enhanced by the baseline scenario; crop allocation changes instead are dampened in nearly all countries. This demonstrates the above said: the increased value of land in the baseline scenario (due to productivity improvements) raises the responsiveness of GTAP to the land allocation changes.

The effect of the coupling on the results of the climate change simulation was studied by reference simulations with the uncoupled models. With both models the climate impacts relative to the afore established benchmark of 2050 were estimated. A clear impact of the coupling can be revealed for both models. The results of standalone simulations generally differ from those of the coupled simulation by some ten up to several hundred percent and show opposite signs for some cases. The differences are lower for the general economic indicators, reflecting the damped responsiveness to land-use changes of the GTAP-EFL due to the tripled elasticity. Land allocation changes in GTAP-EFL standalone and KLUM@GTAP differ by several hundred up to thousand percent. This clearly demonstrates the relevance of the improved allocation mechanism. Moreover the differences are larger for greater yield changes - indicating that the effect of the coupling will be even more pronounced for extreme scenarios.
All these results strongly support the hypothesis that a purely economic, partial equilibrium analysis of land use is biased; general equilibrium analysis is needed, taking into account spatial explicit details of biophysical aspects.

Concluding, the presented approach is a step in the right direction to reach an integrated modelling framework for the estimation of the mutual impacts of economic and environmental changes such as climate change. It establishes a dynamic and close link between the two models, bearing the potential of consistently integrating the biophysical aspects of land-use decisions into the economic model. The flexible spatial resolution of KLUM additionally facilitates the use of a spatial resolution needed for a meaningful biophysical analysis of the environmental aspects. Yet, to really establish a satisfactory modelling framework that allows reliable projections of the integrated changes of the natural and economic system a long way is still ahead. Most pressingly, the presented convergence problems and inconsistency in the interpretation of land quantity need to be resolved. This requires an elaborative revision of some mechanisms in the general equilibrium model and - in all likelihood-a recalibration of the model. A dynamic formulation of GTAP-EFL would help to simulate future pathways with the coupled framework without relying on a baseline scenario with heavy shocks. This would further improve the conditions for convergence. Apart from that, the allocation algorithm of KLUM needs to be extended to include other agricultural sectors such as animal production and finally also forestry and industrial land. The coupling of the land use model to a dynamic vegetation model is already performed for the European level [17]. To reach full integration, both couplings need to be consolidated on the global level. Besides competition for land, the model should be extended to include competition for water resources.

All in all, the presented work should be seen as a first valuable step on the stony path towards a consistent integrated assessment of the economic and environmental impacts of global land use changes.

Acknowledgements We like to thank Katrin Rehdanz for many valuable discussions and helpful comments. Hom Pant and Andrzej Tabeau as well as the other participants of the CGE-Fest held in Hamburg in June 2005 helped to improve the coupling by relevant comments and questions. The Volkswagen Foundation and the Michael Otto Foundation provided welcome financial support.

Open Access This article is distributed under the terms of the Creative Commons Attribution Noncommercial License which permits any noncommercial use, distribution, and reproduction in any medium, provided the original author(s) and source are credited. 


\section{Appendix}

Appendix 1: Aggregations

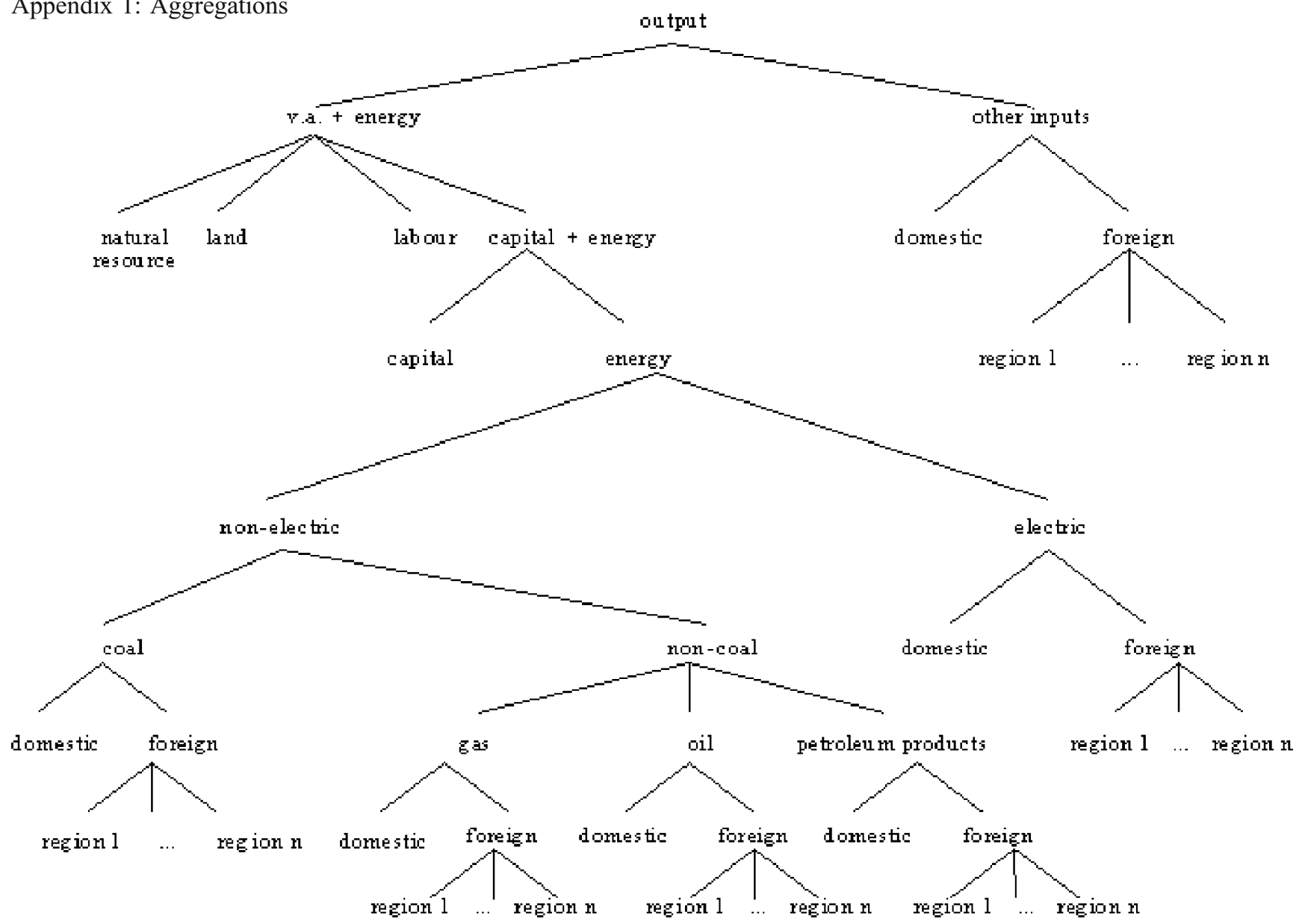

Fig. 7 Industrial production: Nested tree structure for industrial production processes in GTAP-EFL

Fig. 8 Final demand: nested tree structure for final demand in GTAP-EFL

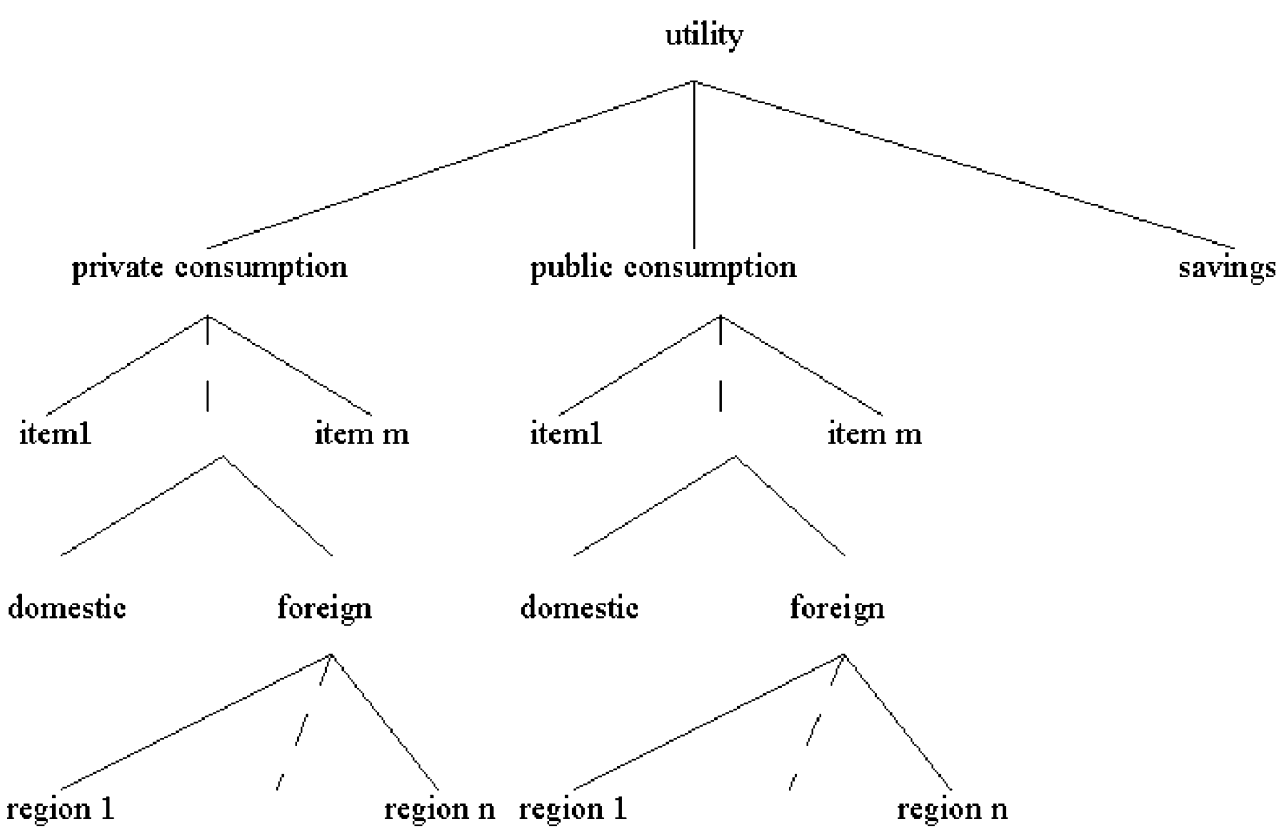


Table 6 Regional aggregation of the coupled model

\begin{tabular}{ll}
\hline & Region \\
\hline USA & USA \\
CAN & Canada \\
WEU & Western Europe \\
JPK & Japan and South Korea \\
ANZ & Australia and New Zealand \\
EEU & Central and Eastern Europe \\
FSU & Former Soviet Union \\
MDE & Middle East \\
CAM & Central America \\
SAM & South America \\
SAS & South Asia \\
SEA & Southeast Asia \\
CHI & China, North Korea \& Mongolia \\
NAF & North Africa \\
SSA & Subsaharan Africa \\
ROW & Rest of the World \\
\hline
\end{tabular}

Appendix 2: Mathematical Formulation of the KLUM Model

The total achievable profit $\pi$ per hectare of one spatial unit is assumed to be:

$\pi=\sum_{k=1}^{n}\left(p_{k} \alpha_{k}-\widetilde{c}_{k} \bar{L} l_{k}\right) l_{k}-\gamma \operatorname{Var}\left[\sum_{k=1}^{n}\left(p_{k} \alpha_{k}-\widetilde{c}_{k} \bar{L} l_{k}\right) l_{k}\right]$

The first part of the equation describes the expected profit, where $p_{k}$ is the price per product unit, $\alpha_{k}$ is the productivity per area and $l_{k}$ denotes the share of total land $\bar{L}$ allocated to crop $k \in\{1 \ldots n\}$ of $n$ crops of $n$ crops. $\widetilde{c_{k}}$ is the cost parameter for crop $k$. Total costs are assumed to increase in land according to $C=\sum_{k=1}^{n} \widetilde{c}_{k} L_{k}^{2}$ where $L_{k}=l_{k} \bar{L}$ denotes the total area allocated to crop $k$.

The second term of the equation represents the risk aversion of the representative land owner. Risk perception is quantified by the variance of the expected profit, weighted by a risk aversion factor $0<\gamma<1$.

Maximising $\pi$ under the constraint that all land shares need to add up to a total not greater than one: $1 \leq \sum l_{k}$, an explicit expression for each land-share $l_{i}$ allocated to crop $i \in\{1 \ldots n\}$ can be derived:

$l_{i}=\frac{\frac{1}{2} \sum_{k=1}^{n} \frac{\beta_{i}-\beta_{k}}{\gamma \sigma_{k}^{2}+c_{k}}+1}{\sum_{k=1}^{n} \frac{\gamma \sigma_{i}^{2}+c_{i}}{\gamma \sigma_{k}^{2}+c_{k}}}$

where for simplicity, $\beta_{k}=p_{k} \alpha_{k}$ displaces the profitability of crop $k, \sigma^{2}=\operatorname{Var}\left[\beta_{k}\right]$ displaces the respective variance and
$c_{k}=\bar{L} \widetilde{c}_{k}$. The temporal variability of total costs is assumed to be negligible compared to the variability of prices and productivities (see [17] for a detailed description of model development and evaluation).

\section{Adjustment of the Cost Parameters in KLUM}

The assumption of decreasing returns to scale underlying the cost structure of KLUM has consequences for the interpretation and transferability of the calibrated cost parameters. We interpret the increasing cost with increasing area share such that the most suitable land is used first and with further use more and more unsuitable land is applied. This implies that the calibrated cost parameters are depending on the total amount of agricultural area assumed in the calibration and on its relative distribution of quality concerning crop productivity. Thus, the cost parameters calibrated for one country cannot simply be adopted in other countries. Instead, these values need to be adjusted according to the differences in total agricultural area. Assuming that the relative quality distribution does not change, a doubling of the total area would imply a bisection of the cost, since the double amount of suitable area would be available. So, the $\operatorname{cost}$ parameter $c_{a}$ of country $a$ is adjusted for country $b$ by scaling it according to:

$c_{b}=c_{a} \frac{L_{a}}{L_{b}}$

where $L_{a}$ and $L_{b}$ represent the total agricultural area of country $b$ and of the original country $a$, respectively. This procedure assures that under identical conditions, the size

Table 7 Sectoral aggregation of GTAP-EFL

\begin{tabular}{ll}
\hline & Sector \\
\hline Rice & Rice \\
Wheat & Wheat \\
CerCrops & Other cereals and crops \\
VegFruits & Vegetable, fruits \\
Animals & Animals \\
Forestry & Forestry \\
Fishing & Fishing \\
Coal & Coal mining \\
Oil & Oil \\
Gas & Natural gas extraction \\
Oil_Pcts & Refined oil products \\
Electricity & Electricity \\
Water & Water collection, purification and distribution services \\
En_Int_ind & Energy intensive industries \\
Oth_ind & Other industry and services \\
MServ & Market services \\
\hline
\end{tabular}


of a country (or rather the amount of agricultural area) does not impact the result.

\section{Appendix 3: Scenario Assumptions}

\section{Baseline Scenario}

Procedure The baseline simulation transfers both models to a consistent benchmark of the future. The values of key economic variables shaping the 1997 equilibrium in GTAP are updated according to likely future changes. This step is done with the GTAP model with endogenous land allocation. The resulting changes, thus, also imply land allocation changes with respect to 1997 . Crop price and land productivity changes are imposed onto KLUM, which also determines land allocation changes relative to 1997. It should be noted that only the deviations from the mean change in land productivity are applied to KLUM; the general mean change implies an increase in costs and riskiness common to all crops and has, thus, less effect for the simulation results. The differences of land allocation changes in KLUM relative to GTAP-EFL are applied to GTAP-EFL with exogenous land allocation on top of the new benchmark; the land allocation in the benchmark is, thus, adjusted to that in KLUM. The results of this simulation mark the final benchmark of the future situation. Corresponding price and yield changes are used to adjust prices and yields in KLUM to the final situation consistent with the benchmark. To test the consistency, a similar loop as in the convergence testing is started. The allocation changes of KLUM relative to the primarily calculated future allocation are fed back to GTAP-EFL in the final benchmark. The resulting price and yield changes are again imposed on KLUM in its final benchmark. Consistency is assured if prices, yields and allocation changes eventually converge to zero.

Data The economic baseline scenario describes the essential changes of key economic variables for 2050 without climate change (see Table 8 ). Instead of relying on current calibration data, we base our exercise on a benchmark forecast of the world economy structure. To this end, we derive hypothetical datasets for 2050 using the methodology described in Dixon and Rimmer [4]. This entails imposing forecasted values for some economic variables on the model calibration data to identify a hypothetical general equilibrium state in the future.

Since we are working on the medium to long term, we focus primarily on the supply side: forecasted changes in the national endowments of labour, capital and population as well as variations in factor-specific and multi-factor productivities. Most of these variables are naturally exogenous in CGE models. For example, the national labour force is usually taken as given. In the baseline scenario, we shock the exogenous variable labour stock, changing its level from that of the initial calibration year

Table 8 Baseline scenario: Exogenous changes in key macroeconomic variables applied in the 2050 baseline

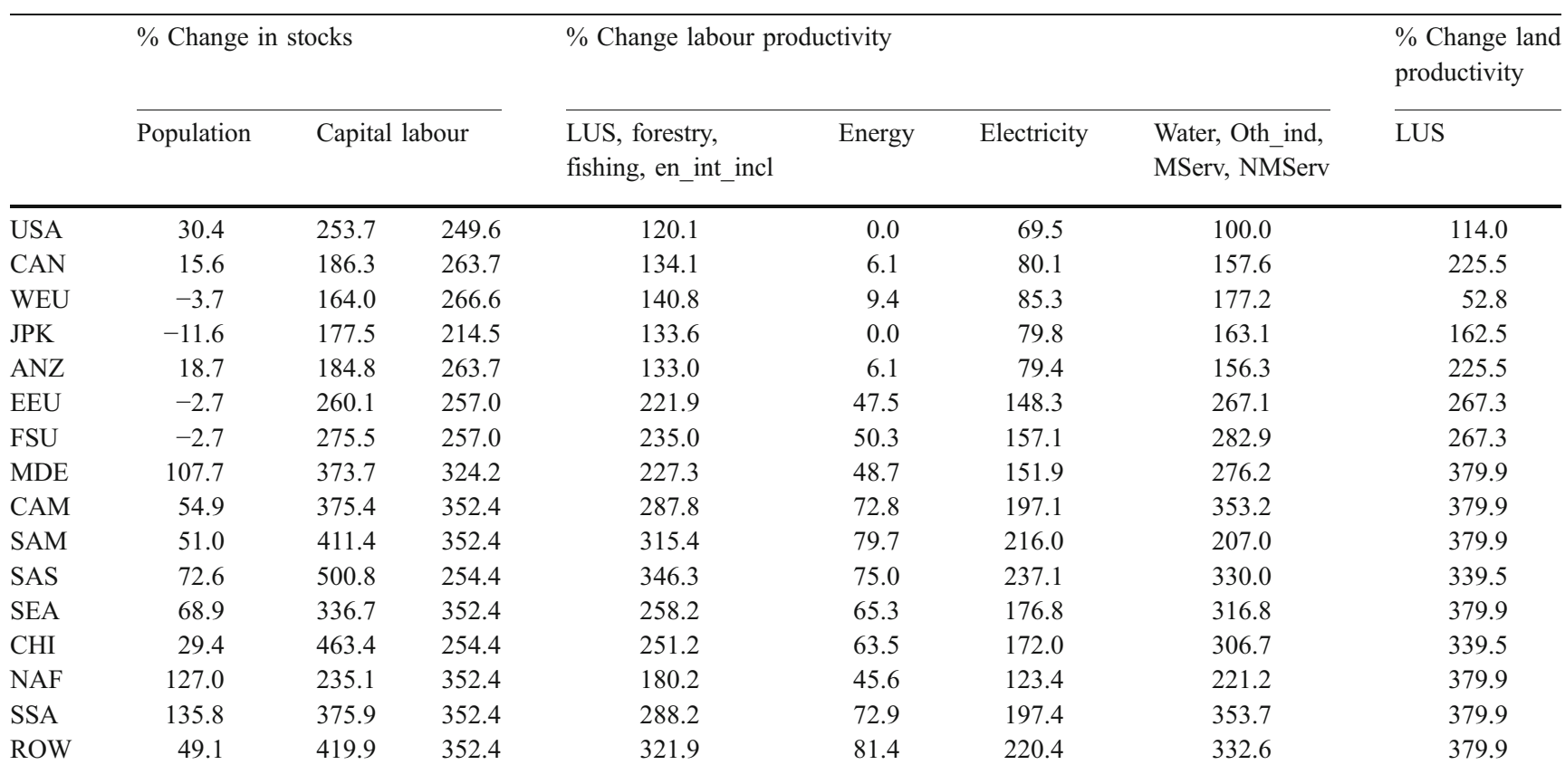

Values are expressed as percentage changes relative to 1997 quantities. With $L U S$, we refer to the land-using sectors Rice, Wheat, CerCrops, VegFruits and Animals; Energy comprise the energy sectors Coal, Oil, Gas and OillPcts. Labour refers to 'effective labor', that is: number of workers times the average productivity per worker. 


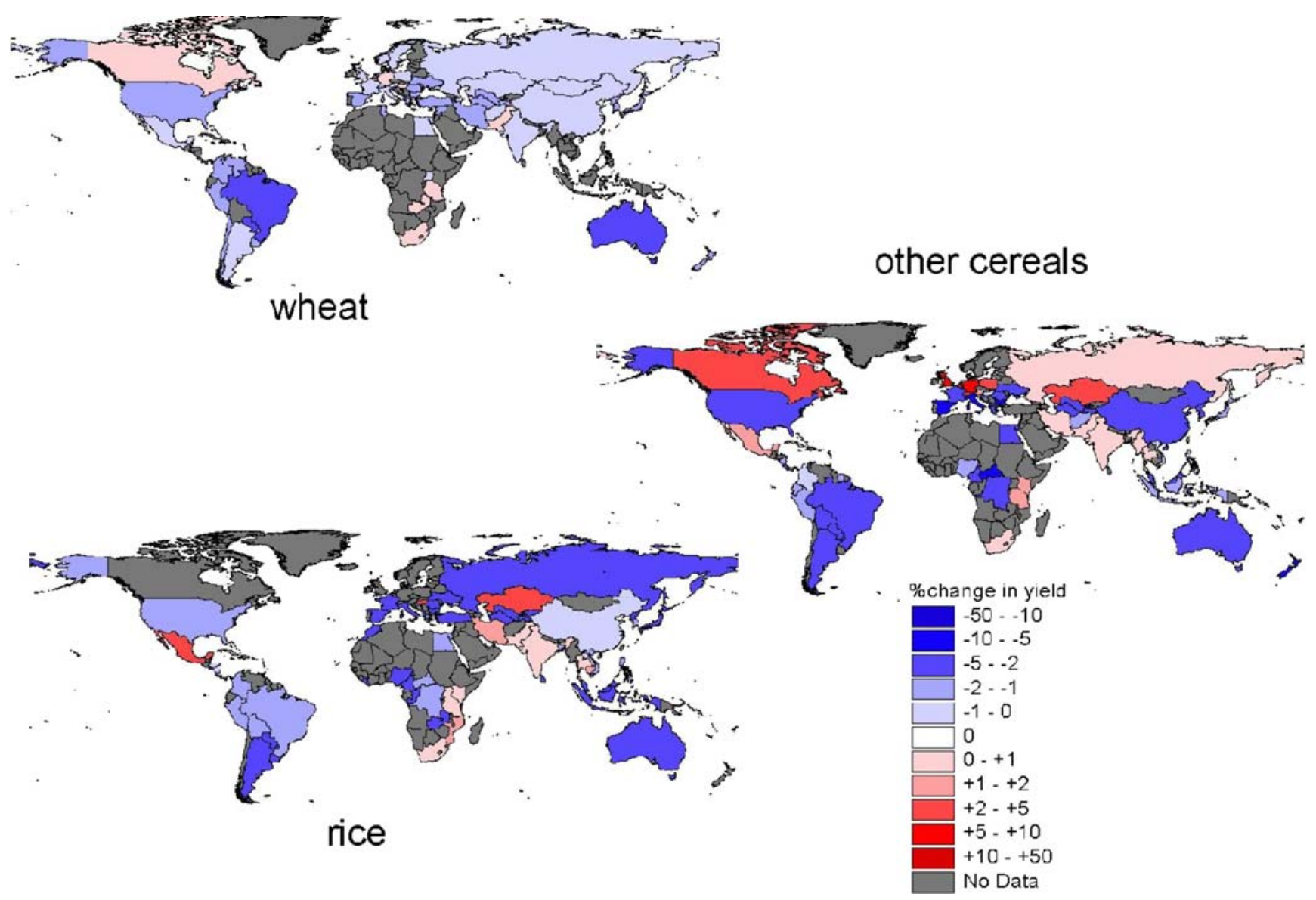

Fig. 9 Climate change scenario: Yield changes assumed in the climate change scenarios. Values are adopted from [20]

(1997) to 2050. In the model, simulated changes in primary resources and productivity induce variations in relative prices and a structural adjustment for the entire world economic system. The model output describes the hypothetical structure of the world economy, which is implied by the selected assumptions of growth in primary factors.

We obtain estimates of the regional labour and capital stocks by running the G-Cubed model [15]. This is a rather sophisticated dynamic CGE model of the world economy, which could have been used-in principle - to directly conduct our simulation experiments. However, we prefer to use this model as a data generator for GTAP, because the latter turned out to be much easier to adapt for our purposes, in terms of disaggregation scale and changes in the model equations.

We get estimates of agricultural land productivity from the IMAGE model version 2.2 (IMAGE 2001). IMAGE is an integrated assessment model, with a particular focus on land use, reporting information about seven crop yields in 13 world regions, from 1970 to 2100 . We run this model by adopting the most conservative scenario about climate change (IPCC B1), implying minimal temperature variations.

\section{Climate Change Simulation}

Procedure To simulate the relative impact of climate change we impose a climate change scenario over the afore established benchmark. We start by applying to KLUM climate-induced yield changes on country level. Resulting allocation changes and the regionally aggregated yield changes are applied to GTAP-EFL and exchanged with crop price and management changes for ten iterations. It should be noted that we correct the management changes of GTAP-EFL (equation 4) for the before imposed climate-induced yield changes. The mean value of the last four iterations is fed back to both models to reach the final results. The convergence path is audited in order to guarantee the consistency of the modeling framework.

Data In our climate change scenario we reduce the effect of a changing climate to its impact on crop yields. The scenario is based on yields presented in Tan and Shibasaki [20], who provide estimates of changes in yield due to climate change of the major crops for several countries around the world. They utilise climate change data from the first version of the Canadian Global Coupled Model ${ }^{4}$ to quantify monthly

\footnotetext{
${ }^{4}$ Provided by the Intergovernmental Panel on Climate Change
} 
minimum and maximum temperature and precipitation. Adaptation is taken into account by means of changing planting dates. The assumed yield changes are relatively small in extent, but similar in sign when compared to estimates of as e.g. Rosenzweig et al. [19] and FAO [5]. We chose the presented source as it offers estimates for a larger amount of countries than the other sources.

Based on these estimates for 2050, we determine potential yields under climate change of wheat, rice and other cereals (see Fig. 9). We use the predictions of yield changes in maize to adjust potential production of other cereals, even though this is an aggregate of many different cereal crops weighted differently in different countries. However, in around half of the simulated countries, maize production makes more than half of the total production of cereal crops and only for around $20 \%$ of all countries this share is below $30 \%$. Thus, we conclude that the applied simplification is acceptable. Potential productions of the vegetables and fruits aggregates are assumed to stay on the level of 1997.

In all simulations the variances $\sigma^{2}$ (compare Eq. 6), reflecting the riskiness of a certain crop in KLUM, are set to the temporal average of past variances and held constant. Throughout all simulations we exclude the region Rest of the World from the coupling and assume the elasticity of substitution for primary factors to be $E S B V \cong 0.711$, which is the triple of the original value.

\section{References}

1. Alcamo, J., Kreileman, G. J. J., Krol, M., \& Zuidema, G. (1994). Modelling the global society-biosphere-climate system: Part 1: Model description and testing. Water, Air, and Soil Pollution, 76, 1-35. doi:10.1007/BF00478335.

2. Burniaux, J. M., \& Truong, T. P. (2002). GTAP-E: An energy environmental version of the GTAP model. West Lafayette: GTAP Technical Paper 16.

3. Darwin, R., Tsigas, M., Lewandrowski, J., \& Raneses, A. (1995). World agriculture and climate change: economic adaptations. Agricultural Economic Report 703. Washington, D.C.: Natural Resources and Environment Division, Economic Research Service, US Department of Agriculture.

4. Dixon, P., \& Rimmer, M. (2002). Dynamic general equilibrium modeling for forecasting and policy. Tech. rept. Amsterdam: Elsevier.

5. FAO (2002). World agriculture: towards 2015/2030. Tech. rept. Rome: FAO.

6. FAO (2003). State of the world's forests 2003. Tech. rept. Rome: FAO.

7. FAOSTAT (2004). http://faostat.fao.org [Accessed: 2004].

8. Fischer, G., van Velthuizen, H., Shah, M., \& Nachtergaele, F. (2002). Global Agro-ecological Assessment for Agriculture in the 21st Century: Methodology and Results. Tech. rept. IIASA Research Report. International Institute for Applied Systems
Analysis, Laxenburg, Austria. Electronic version at http://www. iiasa.ac.at/Publications/Documents/RR-02-002.pdf [Accessed: March, 2005].

9. Grübler, A. (1994). Technology. In Meyer, WB, \& II, BL Turner (eds), Changes in Land Use and Land Cover: A Global Perspective (pp 287-328). Global Change Institute, vol. 4. Press Syndicate of the Universtity of Cambridge.

10. Heistermann, M., Müller, C., \& Ronneberger, K. (2006). Land in sight? Achievements, deficits and potentials of continental to global scale land-use modeling. Agriculture Ecosystems and Environment, 114(2-4), 141-158 22.

11. Hertel, T. W. (1997). Global trade analysis. Cambridge.: Cambridge University Press IMAGE. 2001. The IMAGE 2.2 Implementation of the SRES Scenarios.

12. Klijn, J. A., Vullings, L. A. E., van den Berg, M., van Meijl, H., van Lammeren, R., van Rheenen, T., Veldkamp, A., \& Verburg, P. H. (2005). The EURURALIS study: Technical document. Alterrarapport 1196. Wageningen: Alterra.

13. Lee, H. -L., Hertel, T. W., Sohngen, B., \& Ramankutty, N. (2005). Towards an integrated land use database for assessing the potential for greenhouse gas mitigation. GTAP Technical Paper 25. West Lafayette: GTAP.

14. Leff, B., Ramankutty, N., \& Foley, J. A. (2004). Geographic distribution of major crops across the world. Global Biogeochemical Cycles, 18(1), GB1009. doi:10.1029/2003GB002108.

15. McKibbin, W. J., \& Wilcoxen, P. J. (1999). The theoretical and empirical structure of the gcubed model. Economic Modelling, 16 (1), 123-148. doi:10.1016/S0264-9993(98)00035-2.

16. RIVM (2001). The IMAGE 2.2 model documentation. Tech. rept. National Institute of Public Health and the Environment, Bilthoven, NL. Electronic version at http://arch.rivm.nl/image/ [Accessed Mar. 2005].

17. Ronneberger, K., Tol, R. S. J., \& Schneider, U. A. (2005). KLUM: A simple model of global agricultural land use as a coupling tool of economy and vegetation. FNU Working paper 65. Hamburg University and Centre for Marine and Atmospheric Science, Hamburg, Germany. Electronic version at http://www.unihamburg. de/Wiss/FB/15/Sustainability/KLUM WP.pdf].

18. Ronneberger, K., Criscuolo, L., Knorr, W., \& Tol, R. S. J. (2006). KLUM@LPJ: Integrating dynamic land-use decisions into a dynamic global vegetation and crop growth model to assess the impacts of a changing climate. A feasibility study for Europe. FNU Working paper 113. Hamburg University and Centre for Marine and Atmospheric Science, Hamburg, Germany. Electronic version at http://www.uni-hamburg.de/Wiss/FB/15/Sustainability/ KLUM WP.pdf 9

19. Rosenzweig, C., Parry, M. L., Fischer, G., \& Frohberg, K. (1993). Climate change and world food supply. Research Report 3. Oxford: Environmental Change Unit, University of Oxford.

20. Tan, G., \& Shibasaki, R. (2003). Global estimation of crop productivity and the impacts of global warmings by GIS and EPIC integration. Ecological Modeling, 168, 357-370. doi:10.1016/ S0304-3800(03)00146-7.

21. van Meijl, H., van Rheenen, T., Tabeau, A., \& Eickhout, B. (2006). The impact of different policy environments on agricultural land use in Europe. Agriculture Ecosystems and Environment, 114(1), 21-38. doi:10.1016/j.agee.2005.11.006.

22. World Bank (2003). World development indidcators CD ROM.

23. Zuidema, G., van den Born, G. J., Alcamo, J., \& Kreileman, G. J. J. (1994). Simulating changes in global land-cover as affected by economic and climatic factors. Water, Air, and Soil Pollution, 76, 163-198. doi:10.1007/BF00478339. 